\title{
Aquatic pollution may favour the success of the invasive species A. franciscana
} 2

3 VARÓ $^{1 *}$, I., REDÓN ${ }^{1}$, S., GARCIA-ROGER ${ }^{2}$, E.M., AMAT ${ }^{1}$, F., GUINOT ${ }^{1}$, D., SERRANO ${ }^{3}$, R., 4 NAVARRO ${ }^{1}$, J.C. 5

$6 \quad{ }^{1}$ Instituto de Acuicultura Torre de la Sal (IATS-CSIC), 12595 Ribera de Cabanes, (Castellón), Spain

$7 \quad{ }^{2}$ Cavanilles Institute of Biodiversity and Evolutionary Biology, University of Valencia, Burjassot, Spain

$8 \quad{ }^{3}$ Research Institute for Pesticides and Water (IUPA). Avda. Sos Baynat, s/n. University Jaume I, 12071

9 Castellón, Spain

* Corresponding author: Tel: +34 964319500 ext 25; Fax: +34 964 319509. E-mail: inma@iats.csic.es

\section{Abstract}

The genus Artemia consists of several bisexual and parthenogenetic sibling species. One of them, A. franciscana, originally restricted to the New World, becomes invasive when introduced into ecosystems out of its natural range of distribution. Invasiveness is anthropically favoured by the use of cryptobiotic eggs in the aquaculture and pet trade. The mechanisms of out-competition of the autochthonous Artemia by the invader are still poorly understood. Ecological fitness may play a pivotal role, but other underlying biotic and abiotic factors may contribute. Since the presence of toxicants in hypersaline aquatic ecosystems has been documented, our aim here is to study the potential role of an organophosphate pesticide, chlorpyrifos, in a congeneric mechanism of competition between the bisexual A. franciscana (AF), and one of the Old World parthenogenetic siblings, A. parthenogenetica (PD). For this purpose we carried out life table experiments with both species, under different concentrations of the toxicant $(0.1,1$ and $5 \mu \mathrm{g} / \mathrm{l})$, and analysed the cholinesterase inhibition at different developmental stages. The results evidence that both, AF and PD, showed an elevated tolerance to high ranges of chlorpyrifos, but AF survived better and its fecundity was less affected by the exposure to the pesticide than PD. The higher fecundity of AF is a selective advantage in colonization processes leading to its establishment as NIS. Besides, under the potential selective pressure of abiotic factors, such as the presence of toxicants, its higher resistance in terms of survival and biological fitness also indicates out-competitive advantages.

Keywords: Artemia, invasion, toxicity, chlorpyrifos, life tables, AChE 


\section{Introduction}

Aquatic hypersaline ecosystems (salt lakes, marine and inland solar saltworks, etc...) show very simple trophic structures and very low biodiversity for their conspicuous invertebrate native fauna (Lenz and Browne 1991). Most representative of these invertebrates are the species of the cosmopolitan brine shrimp genus Artemia (Crustacea, Branchiopoda, Anostraca), that show very strong adaptability to diverse hypersaline environments, mediated by a broad tolerance to extremely variable salinities, ionic brine composition, temperatures and oxygen concentrations (Triantaphyllidis et al. 1998; Amat et al. 2005).

The genus Artemia consists of several sibling species. Six bisexual species have been recognized, two of them restricted to the New World: A. franciscana and A. persimilis. The former is the most abundant, and its cysts are commercially available as a natural resource for aquaculture. The other four bisexual species: A. salina, A. urmiana, A. sinica and A. tibetiana, together with a heterogeneous group of obligate parthenogenetic strains recognized as A. parthenogenetica (Muñoz et al. 2010), are restricted to the Old World. In the Mediterranean basin, southern Europe and North Africa, the biodiversity of the genus is reduced to the native sexual A. salina, which sometimes coexists with a variety of diploid and tetraploid parthenogens, with diploids being the most abundant (Amat et al. 1995). Investigations about the comparative biological fitness among different species of the genus, suggest greater physiological, lifespan, reproductive trait and population dynamics differences related to environmental conditions, with important intrinsic variability associated with salinity and temperature (Browne et al. 1988; Browne and Halanych 1989; Barata et al. 1996, Browne and Wanigasekera 2000; Amat et al. 2007; Pinto et al. 2014).

Aside from being a cosmopolitan organism, a wide array of intrinsic characteristics, such as the relatively easy rearing and maintenance of experimental populations under different temperatures and salinities, their resistance to manipulation, short life-cycle, large offspring production, etc., have allowed the brine shrimp Artemia to become an important tool organism in several areas of scientific knowledge, such as ecology, physiology, genetics and aquatic ecotoxicology. Despite some criticisms having been raised against the inclusion of Artemia as a marine-water test organism, because of its absence in marine ecosystems and its presumed lack of sensitivity to chemical exposure due to its conspicuous resistance to extreme salinity conditions (Persoone et al. 1987 ), toxicity bioassays - particularly dealing with marine and brackish water ecosystems - have been proposed using the genus as a test organism as broadly reviewed by Nunes et al. (2006). However, many ecotoxicological studies using brine shrimp Artemia as a test organism do not take into account the biodiversity of the genus. Most often, species or strains of different origin are neither properly identified nor cited in the materials and methods section, or worse, individuals obtained from commercial cysts are mistakenly reported as A. salina in reference to the holotype nomenclature, when the vast majority of commercial cysts (if not all) belong either to parthenogenetic strains or most likely to the American A. franciscana (Crisine et al. 1994; Barahona et al.1994; Venkateswara Rao et al. 2007). So, the current picture is that despite the availability of a substantial amount of information dealing with fundamental aspects of ecotoxicity testing (Nunes et al. 2006), it is possible to state that most of it was produced using A. franciscana, with a generalised lack of data about the proper geographical localization of the origin and characterization of the cysts, species or 
1 populations used in the bioassays. Work performed by Browne (1980), Sarabia et al. (2002) or Varó et al. 2 (1998) showed consistent distinct patterns of response to heavy metals or pesticides, according to different species or strains for testing purposes.

On more empirical grounds, Artemia cysts, i.e. its cryptobiotic eggs, are widely used in aquaculture to produce nauplii that are used as live food for rearing early stages of molluscs, crustaceans and fish. The majority of commercial cysts rely on their natural occurrence in the Great Salt Lake and San Francisco Bay saltworks (United States) (Lavens and Sorgeloos 2000), and this has resulted in the widespread distribution of A. franciscana the world over. For example, field studies carried out in the western Mediterranean region from the early 1980s report the occurrence of exotic A. franciscana populations (Amat et al. 2005). Other anthropogenic activities such as pet trade, or saltwork operations have also contributed to the expansion and dispersion of this American native species, that has become an invasive pest that out-competes and eradicates native A. salina and A. parthenogenetica populations in wetlands and saltworks (Amat et al. 2005; Green et al. 2005), acting as an alien or non indigenous species (NIS, Piola and Johnston 2008). The mechanisms of eradication and out-competition of the autochthonous Artemia by the invader A. franciscana are, however, still poorly understood. It seems clear that the highest ecological fitness of the invader plays a pivotal role, but other less explored, underlying biotic and abiotic (i.e. sensitivity to toxicants) processes, may be affecting.

This study starts from the evidence of the presence of toxicants in the brines of a hypersaline ecosystem, the river Ebro delta salterns, in which the invader A. franciscana has replaced the original autochthonous A. parthenogenetica populations (Serrano et al. 2012). It aimed at studying the potential role played by an organophosphate pesticide namely chlorpyrifos in a congeneric competition mechanism leading to the establishment of this NIS and to the disappearance of the native populations. For this purpose, life table experiments and further demographic analyses were carried out with both species, under different concentrations of the toxicant $(0.1,1$ and $5 \mu \mathrm{g} / \mathrm{l})$, and the cholinesterase inhibition at different developmental stages was analysed.

\section{Materials and Methods}

\subsection{Experimental organisms and conditions}

Two different Artemia populations were used in this study: A. franciscana, a non-indigenous invasive species in Europe original from America (hereafter indicated as AF), and the native diploid $A$. parthenogenetica (hereafter indicated as PD). PD is original from La Mata salt lagoon $\left(38^{\circ} 02^{\prime} 08^{\prime \prime} \mathrm{N}\right.$ 042’30”W) in Torrevieja (Alicante, Spain). AF was introduced in "La Trinitat" saltworks at Alfaques Bay (40³4'58'N 040’48”E) in the river Ebro delta (Tarragona, Spain), and it practically eradicated the parthenogenetic Artemia native populations in this location (Amat et al. 2005).

Original brine shrimp cysts collected in 1988 for La Mata PD and in 2008 for "La Trinitat" AF, and kept at the "Instituto de Acuicultura Torre de la Sal" (IATS) cyst bank, were used. These cysts were hatched in seawater $(35 \mathrm{~g} / \mathrm{l})$ at $28^{\circ} \mathrm{C}$ under $24 \mathrm{~h}$ light photoperiod (1500-2000 lux, using fluorescent 
1 lights) and aeration by air bubbling. Newly hatched nauplii were separated from their empty floating shells and any remaining unhatched cyst was discarded.

Batches of 150 newly hatched nauplii per treatment were separated in order to have sufficient individuals of the same age for life table experiments. From each batch, a total of 5 replicates of 30 early metanauplii were separated and directly transferred to polypropylene corning tubes filled with $50 \mathrm{ml}$ of experimental solution (see below for details). The cultures were kept under conditions of constant temperature, salinity and photoperiod in a thermostatic chamber $\left(24^{\circ} \mathrm{C}, 75-80 \mathrm{~g} / \mathrm{l}, 12 \mathrm{~h}: 12 \mathrm{~h}\right.$ light:darkness), and fed on a mixture of the microalgae Dunaliella salina and Tetraselmis suecica, which is the staple diet for the maintenance of Artemia cultures at IATS. After one week, animals were transferred to $150 \mathrm{ml}$ jars filled with $100 \mathrm{ml}$ of experimental solution. Complete medium renewal was performed every 2-3 days in order to maintain the exposure conditions (concentration of chlorpyrifos in the water and food) as constant as possible (Varó et al. 2000) and to preserve individuals from excessive handling. Previous determinations showed that after $48-72 \mathrm{~h}$ actual concentrations of chlorpyrifos in water were less than 10\% from nominal values (Varó et al. 2000; 2002b) The cultures were maintained in these conditions until the females showed the first signs of vitellogenesis (Sarabia et al. 2008).

\subsection{Chemicals and experimental solutions}

Prior to developing this study, brine and living Artemia biomass samples, collected seasonally over one year (2007) in "La Trinitat" saltworks, were analysed in the Research Institute for Pesticides and Water, University Jaume I in Castellón (Spain). A GC/TOF MS based method was applied in search of organochlorine and organophosphorous contaminants (Serrano et al. 2011; 2012). The pesticide chlorpyrifos was commonly detected in brine and brine shrimp samples. This insecticide is usually applied to protect agricultural crops, mainly rice fields, spread throughout the river Ebro delta (Claver et al. 2006) reaching the Alfaques Bay from where seawater is pumped to be evaporated in "La Trinitat" saltworks for marine salt production.

Chlorpyrifos was obtained from Dr. Ehrenstorfer Reference Materials (Germany). Several stock solutions were prepared by dissolving chlorpyrifos in acetone given the low solubility of chlorpyrifos in saline waters (Varó et al. 2000). The experimental solutions were obtained by serial dilutions of chlorpyrifos stock in filtered $(0.45 \mu \mathrm{m})$ brine $(75-80 \mathrm{~g} / \mathrm{l})$. Three different sublethal chlorpyrifos concentrations were tested: $0.1,1$ and $5 \mu \mathrm{g} / \mathrm{l}$. Two controls were also included. A first control group was exposed to clean brine (C), and a second one was exposed to the same amount of solvent (5 $\mu \mathrm{g} / \mathrm{l}$ acetone, CA) as in the highest concentration tested. The sublethal chlorpyrifos concentrations used were based on previous Artemia studies carried out in our laboratory (Varó et al. 1998; 2000).

\subsection{Life table experiments}

To study the life-history responses of AF and PD to chlorpyrifos a total of 20 females showing signs of vitellogenesis were isolated individually, together with a male in the case of the bisexual AF, in $4050 \mathrm{ml}$ polypropylene corning tubes filled with each of the selected chlorpyrifos concentrations, plus the 
1 as indicated above. Their survival and reproduction were examined every 2-3 days. Afterwards, the 2 culture medium was renewed with the appropriate nominal concentration of the pesticide and microalgae.

3 Dead specimens were removed and replaced during the first 3 days only. Afterwards, stock cultures were 4 kept under the same experimental culture conditions. The experiment end point was established after obtaining ten broods per female or after the death of all individuals (male or female).

To assess the effect of sublethal concentrations of chlorpyrifos on the biological fitness of the $\mathrm{AF}$ and the PD Artemia species, life table experiments were carried out and the following life table traits were examined: (1) temporal parameters: pre-reproductive period (PRP), defined as the time taken to obtain the first brood; period between broods (P/B), defined as time period (in days) elapsed between successive broods. (2) Quantitative parameters (fecundity): total number of broods per female (B), total offspring per female (OFF), total offspring per brood (OFF/B). (3) Type of reproduction: ovoviviparous (nauplii) (OVO) versus encysted (cysts) (OVIP). The quality of reproduction was assessed in the case of the ovoviviparous offspring, through the percentage of viable nauplii $(\mathrm{VN})$ and percentage of dead nauplii plus abortive embryos (NVN). For encysted offspring, the percentage of viable and non-viable cysts (VC and NVC, respectively) was also calculated.

\subsection{ChE activity}

The effect of chlorpyrifos on ChE activity was evaluated in metanauplii (AF: 6 days, PD: 5 days), juveniles (AF: 9 days, PD: 14 days) and adults (AF: between 16 and 21 days, PD: between 21 and 28 days) exposed to the selected pesticide concentrations in the stock cultures and kept in the conditions and stored individually at $-80^{\circ} \mathrm{C}$ until enzymatic analyses were performed.

For enzymatic analyses one metanauplii, juvenile or adult was manually homogenised in 350$500 \mu \mathrm{l}$ of ice-cold phosphate buffer $(100 \mathrm{mM})$, using a microcentrifuge tube pestle. The homogenates obtained from metanauplii and juveniles were used directly for enzymatic determinations, whereas those from adults were first centrifuged at $10.000 \mathrm{~g}$ for $30 \mathrm{sec}$, to remove the biggest remains of tissue, and the resulting supernatant was used for enzyme activity. ChE was assayed by the Ellman method (Ellman et al. 1961) following the procedure described in Varó et al. (2002a) using ATC as substrate, with some modifications. Briefly, $0.1 \mathrm{ml}$ of homogenate was mixed with $0.2 \mathrm{ml}$ of the reaction solution $(30 \mathrm{ml}$ of phosphate buffer $100 \mathrm{mM}, \mathrm{pH}=7.2,1 \mathrm{~mL}$ DTNB $10 \mathrm{mM}$ plus $0.2 \mathrm{ml}$ ATC $75 \mathrm{mM}$ ) and absorbance was read at $415 \mathrm{~nm}$. The activity of ChE was measured in kinetic mode using a TECAN Ultra Evolution microplate reader at $25{ }^{\circ} \mathrm{C}$ for $15 \mathrm{~min}$, after an incubation period of $15 \mathrm{~min}$. Activity was expressed as units $(\mathrm{U}=\mathrm{nmol}$ of substrate hydrolysed per minute) per $\mathrm{mg}$ of protein. Total protein content of the samples was determined by the Bradford method (Bradford 1976) adapted to microplate, using the Bradford Bio-Rad Protein Assay and BSA as standard. The absorbance was read at $595 \mathrm{~nm}$. All enzyme analyses and protein determinations were carried out in triplicate per sample. 
The effects of chlorpyrifos on survival during the life table experiments were analysed using the

2 logrank (Mantel-Cox) test for multiple comparison of survival curves (Bland and Altman 2004). P values

3 were corrected with the Bonferroni method by simultaneously comparing all pairs of curves. Data were tested for normality and homogeneity of variance with Kolmogorov-Smirnov and Levene tests, respectively. The reproductive parameters showing homogeneous variance were compared by one-way ANOVA, followed by post hoc Tukey multiple comparison test. When heterocedasticity was found, differences were checked by the Brown-Forsythe test followed by the Games-Howell test for multiple mean comparisons (Amat et al. 2007). To further process in an integrative manner the results of the life table experiments and explore the relationship within the recorded set of life table traits, each variable from the life table was log-transformed and introduced in a multivariate principal component analysis (PCA) using VARIMAX rotation. Score plots were further generated as a potential pattern recognition tool using the species and the toxic concentrations as labels. Prior to performing PCA, the suitability of data was assessed by the Kaisser-Meyer-Olkin method and Bartlett test of sphericity (Ruiz et al. 2000).

An age-structured matrix model was used to calculate the finite population growth rate $(\lambda)$ for each species and treatment. Sukumaran and Grant (2013) have successfully used this kind of analysis to explore the relative sensitivities of these two species to genotoxins. Therefore, age-specific fertilities $\left(\mathrm{F}_{\mathrm{i}}\right)$ and survival probabilities $\left(\mathrm{P}_{\mathrm{i}}\right)$ were calculated from life table data (see section 2.3) on 5-day intervals and a Leslie matrix was built up for each species and treatment. There were 12 age classes for AF (up to a maximum lifespan of 55-60 days) and 15 age classes for PD (up to a maximum lifespan of 70-75 days). Because cysts do not contribute immediately to population growth rate, $F_{i}$ values were computed on the numbers of viable nauplii observed only. All calculations were based on the birth-flow equations from Caswell (2001).

The finite population growth rate $(\lambda)$ was calculated as the dominant eigenvalue of each Leslie matrix. Then, we conducted a decomposition analysis (De Kroon et al. 1986; Caswell 2001) to determine the differences and contributions of age-specific $\mathrm{P}_{\mathrm{i}}$ and $\mathrm{F}_{\mathrm{i}}$ on $\lambda$ between treatments and controls, separately for each species. Accordingly, we used the control (C) matrices of each species as a baseline against which to measure the effects of increasing levels of chlorpyrifos and the effect of the solvent (CA). Matrix population models were run and analyzed using the popbio package (Stubben and Milligan 2007) in R version 3.0.1 (R Development Core Team 2013).

ChE data were also tested for normality and homogeneity of variance with KolmogorovSmirnov and Bartlett tests, respectively. Deviations from normality were corrected with $\log (\mathrm{x}+1)$ transformation. The effect of chlorpyrifos concentrations on $\mathrm{ChE}$ activity for each development stage was assessed using one-way ANOVA, followed by post hoc Dunnett comparison test to determine significant differences among the concentrations of pesticide assayed relative to the control group. One-way ANOVA and post hoc Tukey multiple comparison tests were also used to determine differences in normal ChE activity of non-exposed animals. A t-test was used to compare the normal range of activity in nonexposed individuals for each developmental stage of the two species. The ChE activity data were further analysed multifactorially by General Linear Model to assess the effect due to toxicant concentration, developmental stage and sex (for the bisexual AF strain only). The partial eta-squared statistics describing the proportion of total variability attributable to each factor was computed. Significant differences were 
1 established at $\mathrm{P}<0.05$. Results are presented as means $\pm \mathrm{SD}$ (standard deviation). Statistical analyses

were carried out using the SPSS 20 software package and the Prism software for MacOS X.

3

\section{Results}

5

3.1. Effect of chlorpyrifos on life table parameters

The effects of chlorpyrifos on survival during life table experiments are shown in Fig. 1. The results of the logrank test for multiple comparisons of survival curves reveal a significant effect of the pesticide concentration on the survival of both Artemia species. The highest concentration of toxicant tested $(5 \mu \mathrm{g} / \mathrm{l})$ produced significantly higher mortality in adults of AF, as compared to the rest of the treatments with exception of the solvent control group (CA). In these experimental groups, 50\% and $60 \%$ survived to the $30^{\text {th }}$ day in the rest of the experimental groups, including the control.

By contrast, PD metanauplii exposed to $5 \mu \mathrm{g} / \mathrm{l}$ of chlorpyrifos reached $100 \%$ mortality after 7 days. The survival of the individuals exposed to $1 \mu \mathrm{g} / \mathrm{l}$ showed significant differences with respect to the rest of the groups. Fifty per cent of the individuals survived to the $8^{\text {th }}$ day, whereas $100 \%$ mortality was reached after 24 days (see Fig. 1).

There was an effect of the acetone treatment on the survival of the two species. Although the survival obtained for this treatment followed a similar trend for both $\mathrm{AF}$ and $\mathrm{PD}$, the differences respect to the control (C) were more apparent in AF due to the higher survival of the latter (Fig. 1).

In general, most of the reproductive parameters measured in both Artemia species (AF and PD) were not affected by toxicant exposure (Tables 1 and 2). In AF, chlorpyrifos concentration significantly affected the fecundity parameters (B, OFF) and the amount of both encysted offspring (VC, NVC). In PD, significant effects were found for temporal parameters $(\mathrm{P} / \mathrm{B})$, as well as for fecundity $(\mathrm{B}, \mathrm{OFF}$ and $\mathrm{OFF} / \mathrm{B}$ ). AF females presented shorter pre-reproductive periods (PPR) and similar periods between broods $(\mathrm{P} / \mathrm{B})$ when compared to PD females. On the contrary, the fecundity of AF females, in terms of total offspring per female (OFF) and total offspring per brood (OFF/B), was higher. Regarding the type of reproduction, both Artemia species displayed a higher percentage of encysted offspring (OVIP), except at the highest chlorpyrifos concentration tested ( 1 and $5 \mu / 1$ for PD and AF, respectively), where equilibrium between oviparism (OVIP) and ovoviviparism (OVO) was found. In AF females, exposure to increasing concentrations of chlorpyrifos caused higher percentages of non-viable offspring ( $N V N$ and NVC), and exposure to $1 \mu \mathrm{g} / \mathrm{l}$ chlorpyrifos produced significantly lower percentage of encysted offspring (VC and NVC). On the contrary, exposure to chlorpyrifos did not significantly affect either the type or the quality of reproduction of PD females.

PCA revealed three components with eigenvalues exceeding 1 , which explained $81 \%$ of total variance, with the first two components accounting for $61 \%$ of total variance (34\% first, $27 \%$ second). 
1 the first component could be associated with reproductive success or fertility. Variables OVIP and VC were associated to the negative side of second component. They opposed NVN, OVO and VN, although these variables were less associated with the positive side. NVC was loosely associated to both components. Thus, the second component could be generally identified with the type of reproduction.

The score plots revealed a clear separation of the cases corresponding to the two Artemia species on the first component (Fig. 2B), whereas no clear separation was found among the cases according to the effects of the different pesticide concentrations (Fig. 2C). AF was clearly associated to the fecundity variables.

\subsection{Population level effects of chlorpyrifos and decomposition analysis}

Population growth rate $(\lambda)$ was substantially reduced from the control in the rest of treatments (CA, 0.1, 1 and $5 \mu \mathrm{g} / \mathrm{l}$ chlorpyrifos) in both species (Table 3). PD had a lower finite growth rate in all cases, and suffered a higher reduction at increasing levels of chlorpyrifos than AF.

The effects of chlorpyrifos on fertility $\left(\mathrm{F}_{\mathrm{i}}\right)$, and the contributions of these effects for both species are shown in Fig. 3A and 4A, respectively. Fertility declined with increasing chlorpyrifos concentration in both species, as reflected by the negative values of differences observed. Positive values observed at advanced age classes in $\mathrm{AF}$ (from CA to $5 \mu \mathrm{g} / \mathrm{L}$ chlorpyrifos) and in PD (only in $\mathrm{CA}$ ) may represent a delay in reproduction due to the toxicant effect. In $\mathrm{AF}$, such a positive difference was greater at higher chlorpyrifos concentration. Fertility differences over age 25-30 in AF, and later over age 35-40 in PD, had no impact on $\lambda$ as evidenced by contributions. Most of the impact of chlorpyrifos on fertility occurred in the range 5-25 days of life in AF, while the range moved upwards to 25-40 days in PD.

The effects of chlorpyrifos on survival probabilities $\left(\mathrm{P}_{\mathrm{i}}\right)$, and the contributions of these effects for both species are shown in Fig. 3B and 4B, respectively. Survival and fertility are measured on different scales, but their contributions to effects on $\lambda$ are all expressed on the same scale, and thus are directly comparable. Chlorpyrifos had almost no effect in survival in AF at concentrations up to $1 \mu \mathrm{g} / \mathrm{l}$. At $5 \mu \mathrm{g} / \mathrm{l}$, it reduced survival probability, especially at later ages. Notwithstanding, the contributions of these effects were negligible. Hence, the finite growth rate in AF was more sensitive to changes in fertility than in survival. On the other hand, chlorpyrifos affected negatively survival probability in PD at all concentrations, especially at older ages. Nonetheless, only the effects during the first 25 days of life make any contribution to the observed reduction in $\lambda$ when PD was exposed to $1 \mu \mathrm{g} / 1$ chlorpyrifos.

\subsection{ChE activity}

The effect of increasing concentrations of chlorpyrifos on ChE activity of metanauplii, juveniles and adults of AF and PD are presented in Fig. 5 and 6, respectively. For AF, adult females exposed to chlorpyrifos showed a significant reduction of $\mathrm{ChE}$ activity at 1 and $5 \mu \mathrm{g} / \mathrm{l}$, whereas in males, the ChE activity of both juveniles and adults significantly decreased in all concentrations tested.

Exposure to 1 and $5 \mu \mathrm{g} / 1$ of chlorpyrifos resulted in significant decreases in ChE activity in PD metanauplii. Since metanauplii died after 7 days of exposure at the highest pesticide concentration (5 
$1 \mu \mathrm{g} / \mathrm{l})$ no samples of juveniles and adults were available for ChE activity determinations in this species.

2 However, significant decreases of the ChE activity were found in juveniles and adults exposed at $1 \mu \mathrm{g} / \mathrm{l}$.

3 No significant effect of the solvent (acetone) on ChE activity was observed (see Fig. 6).

The range of normal ChE activity on non-exposed AF and PD individuals is shown in Fig. 7.

5 The mean $\mathrm{ChE}$ activity values found for $\mathrm{AF}$ were $16.31 \mathrm{U} / \mathrm{mg}$ protein for metanauplii, and 11.99 and 8.62

$6 \mathrm{U} / \mathrm{mg}$ protein for juvenile males and females respectively. Corresponding values for adults were 6.22 and

$7 \quad 5.33 \mathrm{U} / \mathrm{mg}$ for males and females respectively. For PD, normal ChE activity was $12.56 \mathrm{U} / \mathrm{mg}$ protein for 8 metanauplii, $7.99 \mathrm{U} / \mathrm{mg}$ protein for juveniles, and $4.25 \mathrm{U} / \mathrm{mg}$ protein for adults. Normal ChE activity significantly decreased from metanauplii to adults in both Artemia species with the exception of the juvenile AF males. Moreover juvenile AF females, and adult AF females and males, did not display differences in normal ChE activity, whereas for juvenile and adult stages of PD, significant differences were found.

The multifactorial analysis of the ChE activity of AF showed significant effects for sex, toxicant concentration and developmental stage, but the interactions were not significant. Partial eta-squared analysis revealed that variability was mainly explained by the toxicant concentration (eta squared $=$ 0.972 ), followed by sex (eta squared $=0.900$ ) and development stage (eta squared $=0.873$ ). For PD, the multifactorial analysis of the $\mathrm{ChE}$ activity (including metanauplii) revealed a significant effect of the factors' toxicant concentration and developmental stage, as well as the interaction. The variability was explained similarly by both factors (eta squared $=0.778$ and 0.710 for development stage and toxicant, respectively), followed by the interaction whose contribution was clearly inferior (eta squared $=0.356$ ).

\section{Discussion}

Life history traits that make species more invasive have been of continuing interest because of their potential predictive power. Studies on NIS have focused on fitness traits that may predispose species to rapid population expansion (Sakai et al. 2001), i.e. traits related mainly to r-selected life histories, like pioneer use of habitat, short generation time, high fecundity and high growth rates (see Kolar and Lodge 2001). Some authors (O’Connor 1986; Newsome and Noble 1986) assign additional abilities to NIS, such as increased dispersal mechanisms, ability to compete with native species for resources, repeated introductions, tolerance to a broad range of environmental conditions, or ability of females to colonize alone and in association with humans (Ehrlich 1989).

Focusing on Mediterranean aquatic hypersaline environments and their conspicuous native brine shrimp species and strains, it would be logical to assign some of the fitness abilities exposed above to the native diploid A. parthenogenetica. Under temperate conditions, usual in the Mediterranean basin, parthenogenetic diploid brine shrimp strains show physiological responses and demographic traits theoretically superior when facing competition with Mediterranean and Old World bisexual species (Amat 1983; Browne and Halanych 1989; Browne 1992; Barata et al. 1996; Browne and Wanigasekera 2000). But whilst in general, parthenogenetic reproduction associates to very effective and rapid dispersal and colonization mechanisms, the real picture shows the American bisexual A. franciscana going beyond its original range and reaching the Old World, spreading from western (Amat et al. 2005) to eastern (Van 
1 Stappen et al. 2007) geographical extremes. Under the same climatic conditions prevailing in the Mediterranean area, this allochthonous species has been able to develop improved physiological responses and demographic traits comparatively to bisexual and parthenogenetic native species and strains, as several authors have experimentally demonstrated (Varó et al. 2000; Sarabia et al. 2002; Browne and Wanigasekera 2000; Browne et al. 2002; Amat et al. 2007), ultimately becoming an invasive NIS.

The research reported here is based on the utilization of the American brine shrimp species introduced and established in "La Trinitat" saltworks. To date, this seems to be the only hypersaline ecosystem invaded with this NIS in the Spanish western Mediterranean. Prawn culture was developed in these saltworks during the 1980s of the last century (Amat et al. 2007), with the cysts from this species, usually from the original population at Great Salt Lake (Utah, USA), being the natural resource "brine shrimp cysts" most widely available in the global market trade for marine aquaculture (Lavens and Sorgeloos 2000).

Artemia populations inhabiting saltworks in the western Mediterranean area are exposed to a variety of contaminants, which may produce an appreciable toxic stress affecting their survival and reproduction. These compounds seem to be ubiquitous in the biotic compartment of aquatic environments and have been detected in Artemia specimens in previous works (Wang and Simpson 1998). The contamination pattern observed in marine saltworks along the Mediterranean coast shows a great variety of organic compounds, with around a dozen of them (including chlorpyrifos) repeatedly present (Serrano et al. 2011; 2012). Sources of these contaminants are certainly run offs from industries, farms and urbanized areas. According to Serrano et al. (2011; 2012 and bibliography therein) a substantial presence of pollutants in hypersaline environments is expected. They can be concentrated during the formation of brines, and then persist throughout the crystallization process. Among these pollutants the organophosphorous pesticide chlorpyrifos is the only contaminant detected in both water (seawater, brines) and in Artemia biomass in "La Trinitat" saltworks (Serrano et al. 2012). Non-polar organochlorine contaminants, $\mathrm{pp}^{\prime} \mathrm{DDE}$ and PCBs, were also detected in Artemia specimens in these saltworks, but not in brines due to their lipophility. All these pollutants can be recognized as potential threats to vulnerable populations inhabiting the waters of saline ecosystems.

Varó et al. (1998; 2000; 2002b) reported that different Artemia strains show different degrees of sensitivity to toxicants, including organophosphorus and organochlorine compounds, with A. franciscana being one of the most resistant forms. Can this exposure to toxicants act as one of the forces driving the success of the NIS A. franciscana over the native Artemia species, particularly over the diploid parthenogenetic strain?

The results of the life table experiments for survival and reproduction reported here for both Artemia species are in line with those reported in the literature, in that they indicate differences in the sensitivity of the nauplii to acute exposure to organophosphate pesticides, both among species and within strains of the same species (Varó et al. 1998; 2002a). The same is true for metals such as Cd (Sarabia et al. 2002). A decrease in survival after acute and chronic exposure to chlorpyrifos has also been found in different species of Daphnia (Palma et al. 2009; Zalizniak and Nugegoda 2006). Our results also show that survival was more sensitive than reproduction to chlorpyrifos exposure, as observed for these same 
1 two species when exposed to other toxicants (e.g. EMS; Sukumaran and Grant 2013). However, the response of both species in terms of sensitivity to chlorpyrifos was different, since mortality was higher in PD in all concentrations tested. This was reflected in higher reduction percentages on population growth rate at all concentrations tested in PD with respect to AF. It is worthy of note that at $5 \mu \mathrm{g} / \mathrm{l}$ of chlorpyrifos, all animals died before the juvenile stage was reached. Moreover, survival in PD strain exposed to $1 \mu \mathrm{g} / \mathrm{l}$ of chlorpyrifos gradually decreased with time until total mortality was reached at 24 days. At this time, the survival of AF exposed to the same concentration was $80 \%$.

The unavoidable effect of carrier solvent in aquatic toxicology studies has been well acknowledged (Rufli et al. 1998, Hallare et al. 2006, Marquis et al. 2006, Hutchinson et al. 2006). It is worth to note that even though in our study this solvent effect is also present, and quite apparent in CA treatment, the highest acetone concentration used $(5 \mu \mathrm{g} / \mathrm{l})$ was well under the maximum OECD recommendations $(79 \mathrm{mg} / \mathrm{l})$. In both species, the addition of the pesticide at the highest concentration, increased the mortality respect to the CA group, especially in PD where total mortality was reached thus highlighting the effect of the pesticide over the effect of the carrier.

The chronic effects of chlorpyrifos on the reproduction process affected the fecundity of both Artemia species. Also, in PD a reduction in the number of offspring (OFF) was observed at exposure concentrations of $1 \mu \mathrm{g} / 1$. Moreover, changes in the quality of reproduction were found in AF exposed to 1 and $5 \mu \mathrm{g} / \mathrm{l}$ of chlorpyrifos, causing a tendency to produce more non-viable offspring, while in PD the period between broods (P/B) was affected by exposure to $1 \mu \mathrm{g} / 1$ of chlorpyrifos. These results are in line with those described previously for freshwater invertebrates, mainly daphnids, in which a decrease in the offspring production has been reported at concentrations of chlorpyrifos ranging from 0.005 to $0.5 \mu \mathrm{g} / 1$ (Naddy et al. 2000; Zalizniak and Nugegoda 2006; Palma et al. 2009). On the contrary, Printes et al. (2008) did not find a direct effect on life history traits in D. magna exposed to the organophosphate insecticide acephate. All other reproductive parameters studied were not affected by chlorpyrifos exposure in both Artemia species, at least in the sense that no clear concentration-response relationships were observed.

The results also indicated notable differences in tolerance to chronic exposure to chlorpyrifos between both Artemia species. Although, both showed an elevated tolerance to the high range of pesticide tested, AF survived better and its fecundity was less affected by the exposure to the pesticide than PD. In fact, the lowest concentration tested $(0.1 \mu \mathrm{g} / \mathrm{l})$ did not produce changes in survival and reproduction compared with the control. To put these facts into context, it should be borne in mind that $0.1 \mu \mathrm{g} / \mathrm{l}$ is the maximum allowed concentration (MAC) in surface water proposed for chlorpyrifos by the European Community (EEC 2007) in environmental quality standards (EQS). This concentration should provide protection of the aquatic ecosystem against short-term exposure. The annual average quality standard concentration (AA) is the limit established for protection against chronic exposure in EQS. For chlorpyrifos, the AA has been established at $0.04 \mu \mathrm{g} / 1$, which is 25 fold lower than the concentration producing negative effect in survival and reproduction in PD $(1 \mu \mathrm{g} / \mathrm{l})$, and 125 fold lower than the concentration that affects $\mathrm{AF}$ in this study $(5 \mu \mathrm{g} / \mathrm{l})$. In general, the life history traits in AF were characterized by shorter pre-reproductive periods and higher reproductive outputs, in terms of fecundity and offspring quality, than those showed by PD, confirming the finding of Amat et al. (2007) for different 
1 populations and species of Artemia. Consistently, PCA analysis of the reproductive parameters revealed a clear separation by Artemia species, whereas exposure to toxicant had not a clear effect in this separation.

The results of our decomposition analysis allow the examination of how much of the change caused by chlorpyrifos on the finite growth rate can be attributed to survival and how much to reproduction. From our results, it follows that all demographically important effects of chlorpyrifos occurred at early ages in both species, but in a different manner for each. Chlorpyrifos had sizable effects on survival and fertility at advanced ages in all concentrations tested for both AF and PD, however these effects had negligible impact on their respective population growth rates. Chlorpyrifos reduced population growth rate in AF by reducing fertility during the first 35 days of life, as evidenced by the differences plots (Fig. 3A, left panels). The contributions of age-specific fertilities to population growth rate (Fig. 3A, right panels) were higher than age-specific survival probabilities, which were not affected by chlorpyrifos in this species (Fig. 3B, right panels). On the other hand, the population growth rate in PD was more affected by the effects of chlorpyrifos on age-specific survival probabilities than on fertilities, the effects being noticeable at $1 \mu \mathrm{g} / \mathrm{l}$ of chlorpyrifos, but fatal at the highest concentration tested.

It is worthy to remind here that we did not consider the production of dormant cysts for the computation of age-specific fertilities, as these propagules do not necessarily contribute to current population growth rates. Sukumuran and Grant (2013) pointed out that considering cysts for the computation of fertilities causes inflated values of population growth rates, although these authors also stressed the role of cysts in long-term persistence of these populations in ephemeral waterbodies. Furthermore, Varó et al. (2006) have shown that the chorion of Artemia cysts acts as a barrier slowing down the entry of chlorpyrifos into the embryo, and that chlorpyrifos has little effect on hatching. Here, we opted for being conservative because direct hatching rates of AF and PD cysts exposed to the chlorpyrifos concentrations assayed in this study were not available for each age class, so we could not reliably estimate the numbers of nauplii hatched from cysts contributing to age-specific fertilities.

The ChE activity was affected after chlorpyrifos exposure in both Artemia species, which confirmed the relevance of $\mathrm{ChE}$ as biomarker of exposure in invertebrates, as shown in previous studies on Artemia and Daphnia (Varó et al. 2002a; Barata et al. 2004). Differences in ChE sensitivity to chlorpyrifos were found between developmental stages. The ChE activity of juveniles and adults of both species was lower than in metanauplii, with the exception of the AF juvenile females that did not show significant inhibition of the enzyme activity in any of the concentrations tested (see Fig 5). Our results show that exposure to the highest chlorpyrifos concentrations ( 1 and $5 \mu \mathrm{g} / \mathrm{l})$ led to a reduction of up to 80 and $85 \%$ of the ChE activity for adults of AF and PD, respectively, before death occurs. It is interesting to stress that, although in more reduced numbers as compared to that of the control, both species are able to produce offspring (Table 1 and 2). In the results of a previous study (Varó et al. 2002a), similar levels of ChE inhibition were obtained for nauplii of the same $A$. parthenogenetica strain and for the bisexual $A$. salina, after $24 \mathrm{~h}$ of exposure to their median lethal concentration (LC50) values of chlorpyrifos without lethal effects. No differences in ChE activity in non-exposed individuals for the same stage of development were obtained between both Artemia species. An inverse relationship between ChE activity and developmental stage has been found, coinciding with the results of previous studies carried out with marine crustaceans and fish by Solé et al. (2006). These authors found a negative correlation between 
1 AChE activity and size in Hake (Merluccius merluccius), and in Norway lobster (Nephrops norvegicus).

2 A similar inverse relationship between body size and acetylcholinestease (AChE) has been described in

3 D. magna (Printes et al. 2003).

Most probably the invasibility triggered by the American brine shrimp is fairly supported by its association to human activities, especially marine aquaculture and pet trade. These anthropic interventions tend to strengthen the role of propagule pressure, provoking and supporting the invasion.

7 They are related to the number of releases and/or the number of individuals released in a fit environment.

8 If these increase, propagule pressure also increases, determining the successful establishment of a NIS

9 (Lockwood et al. 2005). Besides, the successful invasion by the sexual species may be favored by a 10 combination of high genetic diversity, high fitness, persistence in the cyst bank, and putative presence of 11 negative factors affecting the parthenogenetic native populations (i.e. presence of toxicants). Although 12 our results indicate a high tolerance to chronic exposure by chlorpyrifos of both Artemia species, the 13 features achieved by bisexual reproduction may allow advantages to persist that, in harsh environments 14 such as hypersaline biotopes polluted with xenobiotics, change into specific adaptations leading to maximizing individual survival, for example through the r-strategy. As a consequence of this selective pressure, sexual organisms reproduce quickly and in great numbers, developing shorter maturation times, even with lower nutrient requirements, as opposed to their asexual counterparts (Lin and Lin 2010). Such a combination of rapid population growth with the maintenance of genetic diversity, typically eroded in parthenogenetic species (Butlin 2002, Mergeay et al. 2006), would explain invasion success in bisexual $A$. franciscana. Interestingly, a similar mechanism has been proposed to explain the resistance to invasibility in a population of sexual Daphnia pulex against asexual clones of the same species (Innes and Ginn 2014).

According to the intrinsic characteristics of hypersaline environments (high biological productivity and low biodiversity), resource limitation is less likely to inhibit an invasion or colonization, and species richness should have little influence on invasion success (Hobbs and Huenneke 1992; Davis et al. 2000; Kennedy et al. 2002). Disturbance in these systems usually disrupts the behavior of individuals, reducing population fitness and raising the probabilities of success for invading colonists (Davis et al. 2000). The American A. franciscana is an interesting case of expanding species exhibiting a high genetic diversity, part of which is correlated with key fitness traits, contributing to its invasibility capabilities (Gajardo and Beardmore 1989; Pilla and Beardmore 1994; Kappas 2001). Increased genetic diversity was found in many other introduced species (Vidal et al. 2010), resulting from a combination of multiple local introductions of several, or the same, alien origin (Kolbe et al. 2008), that led to numerous translocations from the sites of introduction. This genetic diversity, broadly displayed by the females from the original Great Salt Lake population (Gajardo and Beardmore 1989) provides adaptive responses to variable environmental conditions (Gajardo et al. 2002). Among these, the presence of disturbing xenobiotics including chlorpyrifos should not be disregarded. It could be the basis of an important adaptation into its original range, as well as into the invaded areas (i.e. here in "La Trinitat" salterns 30 years after its arrival). Information dealing with the presence of xenobiotics in continental American basins unveils the presence of diverse chlorpyrifos levels in streams draining agricultural settings and 
1 urban areas to important hydrological basins, levels that sometimes exceed criteria established for the protection of aquatic life (Larson et al. 1999).

This may not be the case for the native diploid A. parthenogenetica populations. Geographically more widely distributed than their sexual relatives, their success relies partially on the existence of a controversial general purpose genotype (GPG) (Van Doninck et al. 2002), able to compensate the low genetic plasticity in parthenogenetic lineages. This genotype probably explains the flourishing asexual organisms in certain environments, based in reproductive efficiency, faithful replication of this GPG, and the generation of specialized genotypes, contrasting with the restricted geographic distribution and strong genetic structure of sexual Artemia species. But, despite the broad expansion of parthenogens, possibly facilitated by an increased availability of suitable habitats provided by anthropogenic activities (Muñoz and Pacios 2010), the absence of mechanisms for rapid genetic change, that has earned asexuals the label of evolutionary dead ends (Butlin, 2002), is on the basis of their limitation in the genetic plasticity necessary to resist in disturbed environments, especially those polluted with new xenobiotics.

\section{Conclusion}

16

The results of this study evidence that both AF and PD showed an elevated tolerance to high ranges of chlorpyrifos, but AF survived better and its fecundity was less affected by the exposure to the pesticide than PD. The higher fecundity of AF is a selective advantage in colonization processes leading to its establishment as NIS. Besides, under the potential selective pressure of abiotic factors, such as the presence of toxicants, its higher resistance in terms of survival and biological fitness also indicates outcompetitive advantages.

\section{Acknowledgments}

This research was supported by the Spanish Ministry for Science and Innovation projects 


\section{References}

2

Amat, F., 1983. Zygogenetic and parthenogenetic Artemia in Cádiz sea-side salterns. Mar. Ecol. Prog. Ser. 13, 291-293.

Amat, F., Barata, C., Hontoria, F., Navarro, J.C., Varó, I., 1995. Biogeography of the genus Artemia (Crustacea, Branchiopoda, Anostraca) in Spain. Intern. J. Salt lake Res. 3, 175-190.

Amat, F., Hontoria, F., Ruiz, O., Green, A.J., Sánchez, M.I., Figuerola, J., Hortas , F., 2005. The American brine shrimp as an exotic invasive species in the Western Mediterranean. Biol. Inv. 7, $37-47$.

Amat, F., Hontoria, F., Navarro, J.C., Vieira, N., Mura, G., 2007. Biodiversity loss in the Genus Artemia in the Western Mediterranean Region. Limnetica 26, 177-194.

Barahona-Gomariz, M.V., Sanz-Barrera, F., Sánchez-Fortún, S., 1994. Acute toxicity of organic solvents on Artemia salina. Bull. Environ. Contam. Toxicol. 52, 766.

Barata, C., Hontoria, F., Amat, F., Browne, R., 1996. Competition between sexual and parthenogenetic Artemia: temperature and strain effects. J. Exp. Mar. Biol Ecol. 196, 313-328.

Barata, C., Solayan, A., Porte, C., 2004. Role of B-esterases in assessing toxicity of organophosphorus (chlorpyrifos, malathion) and carbamate (carbofuran) pesticides to Daphnia magna. Aquat. Toxicol. 66, 125-139.

Bland, J.M., Altman, D.G., 2004. "The logrank test". British Medical Journal 328.

Bradford, M., 1976. A rapid and sensitive method for the quantification of microgram quantities of protein utilising the principle of protein binding. Anal. Bioch. 72, 248-254.

Browne, R.A., 1980. Acute response versus reproductive performance in five strains of brine shrimp exposed to copper sulphate. Mar. Environ. Res. 3, 185-193.

Browne, R.A., Davis, L.E., Salle, S.E., 1988. Effects of temperature and relative fitness of sexual and asexual brine shrimp Artemia. J. Exp. Mar. Biol. Ecol. 124, 1-20.

Browne, R.A., Halanych, K.M., 1989. Competition between sexual and parthenogenetic Artemia: a reevaluation (Branchiopoda, Anostraca). Crustaceana 57 57-71.

Browne, R.A., Wanigasekera, G., 2000. Combined effects of salinity and temperature on survival and reproduction of five species of Artemia. J. Exp. Mar. Biol. Ecol. 244, 29-44.

Browne, R.A., Moller, V., Forbes, V.E., Depledge, M.H., 2002. Estimating genetic and environmental components of variance using sexual and clonal Artemia. J. Exp. Mar. Biol. Ecol. 267, 107-119.

Butlin, R., 2002. The costs and benefits of sex: new insights from old asexual lineages. The costs and benefits of sex: new insights from old asexual lineages. Nature Rev. Gen.3, 311-317. doi:10.1038/nrg749

Caswell, H., 2001. Matrix population models: construction, analysis and interpretation, second ed. Sinauer and Associates, Sunderland, MA.

Charnov, E.L., Schaffer, W.M., 1973. Life history consequences of natural selection: Cole's result revisited. Am. Nat. 107, 791-793.

Claver, A., Ormad, P., Rodríguez, L., Ovelleiro, J.L., 2006. Study of the presence of pesticides in surface waters in the Ebro river basin (Spain). Chemosphere 64, 1437-1443. 
1 Commission (E.E.C.), 2007. European Parliament and the Council European Parliament legislative resolution of 22 May 2007 on the proposal for a directive on environmental quality standards in the field of water policy and amending Directive 200/60/EC.

Crisine, A., Delaunay, L., Rossel, D., Tarradellas, J., Meyer, H., Saiah, H., Vogel, P., Delisle, C., Blaise, C., 1994. Cysts-Based ecotoxicological tests using Anostracans: Comparision of two species of Streptocephalus. Env. Tox. Water Qual. 9, 317.

Crooks, J., Chang, A., Ruiz, G., 2011. Aquatic pollution increases the relative success of invasive species. Biol. Invasions 13, 165-176.

Davis M.A., Grime, J.P. and Thompson, K., 2000. Fluctuating resources in plant communities: a general theory of invisibility. J. Ecol. 88, 528-534.

De Kroon, H., Plaisier, A., van Groenendael, J, Caswell, H., 1986. Elasticity: the relative contribution of demographic parameters to population growth rate. Ecology 67, 1427-1431.

Ehrlich, P.R., 1989. Attributes of invaders and the invading processes. Wiley \& Sons, New York.

Ellman, G.L., Courtney, D., Andres, V., Jr., Featherstone, R.M., 1961. A new and rapid colorimetric determination of acetylcholinesterase activity. Biochem. Pharmacol. 7, 88-95.

Elton, C.S., 1958. The Ecology of Invasions by Animals and Plants. Methuen, London.

Gajardo, G.M., Beardmre, J.A., 1989. Ability to switch reproductive mode in Artemia is related to maternal heterozygosity. Mar. Ecol. Progr. Ser. 55, 191-195.

Gajardo, G., Parraguez, M., Beardmore, J.A., Sorgeloos, P., 2002. Reproduction in the brine shrimp Artemia: evolutionary relevance of laboratory cross-fertility tests. J. Zool. London 253, 25-32.

Green A.J., Sánchez M.I., Amat F., Figuerola F., Hontoria F., Hortas F., 2005. Dispersal of invasive and native brine shrimp Artemia (Anostraca) via waterbirds. Limnol. Oceanogr. 50, 737-742.

Hallarea, A., Nagela, K., Köhlera, H.-R., Triebskorna, R., 2006. Comparative embryotoxicity and proteotoxicity of three carrier solvents to zebrafish (Danio rerio) embryos. Ecotoxicol Environ Saf 63, 378-388.

Hobbs R.J. and Huenneke L.F., 1992. Disturbance, diversity and invasion: implications for conservation. Conserv. Biol. 6, 324-337.

Hutchinson, T.H., Shillabeer , N., Winter, M.J., Pickford, D.B., 2006. Acute and chronic effects of carrier solvents in aquatic organisms: A critical review. Aquat. Toxicol.76, 69-92.

Innes, D.J. Ginn, M. 2014. A population of sexual Daphnia pulex resists invasion by asexual clones. Proc. R. Soc. B 281, 20140564. http://dx.doi.org/10.1098/rspb.2014.0564.

Kappas, I., 2001. Microevolution and genetic differentiation in brine shrimp Artemia Ph.D. Thesis. University of Wales Swansea, Wales. U.K.

Kennedy T.A., Nacem S., Howe K.M, Knops J.M.H, Tilman D, Reich P., 2002. Biodiversity as a barrier to ecological invasion. Nature 417, 636-638.

Knight, K.S., Reich, P.B., 2005. Opposite relationships between invasibility and native species richness at patch versus landscape scales. Oikos 109, 81-88.

Kolar, C.S., Lodge, D.M., 2001. Progress in invasion biology: predicting invaders. Trends Ecol. Evol. 16, 199-204. 
1 Kolbe, J.J. Larson, A., Losos, J.B., de Queiroz, K., 2008. Admixture determines genetic diversity and population differentiation in the biological invasion of a lizard species. Biol. Lett. 4, 434-437.

Larson, S.J., Gilliom, R.J., Capel, P.D., 1999. Pesticides in streams of the United States. Initial results from the National Water-Quality Assessment Program. US Geological Survey.Wat. Res. Inv.

Lavens, P., Sorgeloos, P., 2000. The history, present status and prospects of the availability of Artemia cysts for aquaculture. Aquaculture 181, 397-403.

Lenz , P.H., Browne, R.A., 1991. Ecology of Artemia in: Browne, R.A., Sorgeloos ,P. and Trotman, C. (Ed.), Artemia Biology. CRC Press, Boca Raton, Florida., pp. 237-253.

Lin, R.J., Lin, F., 2010. Coerced group collaborative evolution as an explanation for sexual reproduction's prevalence. Natural Science 2, 1253-1263.

Lockwood, J.L., Cassey, P., T., B., 2005. The role of propagule pressure in explaining species invasions. Trends Ecol. Evol. 20, 223-228.

Lonsdale, W.M., 1999. Global patterns of plant invasions and the concept of invisibility. Ecology 80, 14 $1522-1536$.

Marquis, O., Millery, A., Guittonneau, S., Miaud , C., 2006. Solvent toxicity to amphibian embryos and larvae. Chemospere 63, 8889-8892.

Mergeay, J., Verschuren, D., De Meester, L., 2006. Invasion of an asexual American water flea clone 18 throughout Africa and rapid displacement of a native sibling species. Proc. R. Soc. B 273, 2839 19 - 2844. (doi:10.1098/rspb.2006.3661).

Muñoz, J., Gómez, A., Green, A.J., Figuerola, J., Amat, F., Rico, C., 2010. Evolutionary Origin and Phylogeography of the Diploid Obligate Parthenogen Artemia parthenogenetica (Branchiopoda: Anostraca). PLoS ONE 5(8): e11932. doi:10.1371/journal.pone.0011932

Naddy, R.B., Johnson, K.A., Klaine, S.J., 2000. Response of Daphnia magna to pulsed exposures of chlorpyrifos. . Enviro. Toxicol. Chem. 19, 423-431.

Newsome, A.E., Noble, I.R., 1986. Ecological and physiological characters of invading species. in: R.H. Groves, J.J.B. (Ed.), Ecology of Biological Invasions. Cambridge Univ. Press Cambridge, pp. 120 (166pp).

Nunes, B.S., Carvalho, F.D., Guilhermino, L.M., G., V.S., 2006. Use of the genus Artemia in ecotoxicity testing. Environ. Pollut. 144, 453-462.

Muñoz, J. and Pacios, F., 2010. Global diversity and geographical distribution of diapausing aquatic invertebrates: the case of the cosmopolitan brine shrimp Artemia (Branchiopoda, Anostraca). Crustaceana 83, 465-480.

O’Connor, R.J., 1986. Biological characteristics of invaders among bird species in Britain. Philos. Trans. R. Soc. London Ser.B 314: 583-598. Philos. Trans. R. Soc. London Ser. B 314, 583-598.

Palma, P., Palma, V.L., Fernandes, R.M., Bohn, A., Soares, A.M.V.M., Barbosa, I.R., 2009. Embryotoxic effects of environmental concentrations of chlorpyrifos on the crustacean Daphnia magna. Ecotoxicol. Environ. Safe. 72, 1714-1718.

Persoone, G., Wells, P.G., Sorgeloos, P., Bengtson, D.A., Decleir, W., Jaspers, E., 1987. Artemia in aquatic toxicology: a review. in: Sorgeloos, P., Bengtson, D.A., Decleir, W., Jaspers, E. (Ed.), 
Artemia Research and its Applications. Morphology, Genetics, Strain Characterization, Toxicology Universa Press, Wetteren, Belgium, pp. 259.

Pilla, E.J., and Beardmore, J.A., 1994. Genetic and morphometric differentiation in Old World bisexual species of the brine shrimp Artemia. Heredity 73, 47-56.

Pinto P.M., Hontoria F., Vieira N., Bio A., 2014. Portuguese native Artemia parthenogenetica resisting invasion by Artemia franciscana. Assesing reproductive parameters under different environmental conditions. Estuar. Coast. Shelf Sci. 145, 1-8.

Piola, R.F., Johnston, E.L., 2008. Pollution reduces native diversity and increases invader dominance in marine hard-substrate communities. Div. Distr.14, 329-342.

Printes, L.B., Callaghan, A., 2003. Intraclonal variability in Daphnia acetylcholinesterase. Environ.Toxicol. Chem. 22, 2042-2047.

Printes, L.B., Fellowes, M.D.E., Callaghan, A., 2008. Clonal variation in acetylcholinesterase biomarkers 13 14

R Development Core Team, 2013. R: A language and environment for statistical computing. R Foundation for Statistical Computing, Vienna, Austria. ISBN 3-900051-07-0, URL http://www.R-project.org.

Ricciardi, A., Cohen, J., 2007. The invasiveness of an introduced species dose not predicts its impact. Biol. Inv. 9, 309-315.

Roff, D.A., 1992. The evolution of life histories: theory and analysis. Chapman and Hall, New York.

Rufli, H., Fisk, P.R., Girling, A.E., King, J.M.H., Länge, R., Lejeune, E.X., Stelter, N., Stevens, C., Suteau, P., Tapp, J., Thus, J., Versteeg, D.J., Niessend, H.J., 1998. Aquatic toxicity testing of sparingly soluble, volatile, and unstable substances and interpretation and use of data. Ecotoxicol. Environ. Safe. 39, 72-77.

Ruiz, G.M., Fofonoff, P.W., Carlton, J.T., Wonham, M.J., Hines, A.H., 2000. Invasion of coastal marine communities in North America: apparent patterns, processes, and biases. Annu. Rev. Ecol. Syst. $31,481-531$.

Sakai AK, Allendorf FW, Holt SH, et al. 2001. The population biology of invasive species. Annu. Rev. Ecol. Syst. 32, 305-332.

Sarabia, R., Del, R.J., Varó, I., Diaz-Mayans, J., Torreblanca, A., 2002. Comparing the acute response to cadmium toxicity of nauplii from different populations of Artemia. Environ. Toxicol. Chem. 21, 437-444.

Sarabia, R., Del Ramo, J., Varó, I., Diaz-Mayans, J., Torreblanca, A., 2008. Sublethal zinc exposure has a detrimental effect on reproductive performance but not on the cyst hatching success of Artemia parthenogenetica. Sci. Total Environ. 398, 48-52.

Serrano, R., Nácher-Mestre, J., Portolés, T., Amat, F., Hernández, F., 2011. Non-target screening of organic contaminants in marine salts by gas chromatography coupled to high-resolution time-offlight mass spectrometry. Talanta 85, 877-884.

Serrano, R., Portolés, T., Blanes, M.A., Hernández, F., Navarro, J.C., Varó, I., Amat, F., 2012. Characterization of the organic contamination pattern of a hypersaline ecosystem by rapid 
screening using gas chromatography coupled to high resolution time-of-flight mass spectrometry. Sci. Total Environ. 433, 161-168.

Shea, K., Chesson, P., 2002. Community ecology theory as a framework for biological invasions. Trends Ecol. Evol. 17, 170-176.

Solé, M., de la Parra, L.M.G., Alejandre-Grimaldo, S., Sardá, F., 2006. Esterase activities and lipid peroxidation levels in offshore commercial species of the NW Mediterranean Sea. Mar. Poll. Bull. 52, 1708-1716.

Stearns, S., 1992. The evolution of life histories. Oxford Press, Oxford, UK.

Stubben, C.J., Milligan, B.G., 2007. Estimating and Analyzing Demographic Models Using the popbio Package in R. J. Stat. Softw. 22:11.

Sukumaran, S., Grant, A., 2013. Multigenerational demographic responses of sexual and asexual Artemia to chronic genotoxicity by a reference mutagen. Aquat. Toxicol. 144-145, 66-74.

Torchin, M.E., Lafferty, K.D., Dobson, A.P., McKenzie, W.J., Kuris, A.M., 2003. Introduced species and their missing parasites. Nature 421, 628-630.

Triantaphyllidis, G.V., Abatzopoulos, T.J., Sorgeloos, P., 1998. Review of the biogeography of the genus

Van Doninck, K., De Bruyn, L., Schön, I., Martens, K., 2002. A general purpose genotype in an ancient 18

Van Stappen G., Yu H., Wang X., Hoffman S., Cooreman K., Bossier P., Sorgeloos P. 2007. Occurrence of allochthonous Artemia species in the Bohai Bay rea, PR China, as confirmated by RFLP analysis and laboratory culture tests. Arch. für Hydrobiol. 170, 21-28.

Varó, I., Serrano, R., Navarro, J.C., López, F.J., Amat, F., 1998. Acute lethal toxicity of the organophosphorus pesticide chlorpyrifos to different species and strains of Artemia. Bull. Environ. Contam. Toxicol. 61, 778.

Varó, I., Serrano, R., Pitarch, E., Amat, F., Lopez, F.J., Navarro, J.C., 2000. Toxicity and bioconcentration of chlorpyrifos in aquatic organisms: Artemia parthenogenetica (Crustacea), Gambusia affinis, and Aphanius iberus (Pisces). Bull. Environ. Contam. Toxicol. 65, 623-630.

Varó, I., Navarro, J.C., Amat, F., Guilhermino, L., 2002a. Characterisation of cholinesterases and evaluation of the inhibitory potential of chlorpyrifos and dichlorvos to Artemia salina and Artemia parthenogenetica. Chemosphere 48, 563-569.

Varó, I., Serrano, R., Pitarch, E., Amat, F., Lopez, F.J., Navarro, J.C., 2002b. Bioaccumulation of chlorpyrifos through an experimental food chain: study of protein HSP70 as biomarker of sublethal stress in fish. Arch. Environ. Contam. Toxicol. 42, 229-235.

Varó, I., Amat, F., Navarro, J.C., Barreda, M., Pitarch, E., Serrano, R., 2006. Assessment of the efficacy of Artemia sp (Crustacea) cysts chorion as barrier to chlorpyrifos (organophosphorus pesticide) exposure. Effect on hatching and survival. Sci. Total Environ. 366, 148-153.

Venkateswara Rao, J., Kavitha, P., Jakka, N.M., Sridhar, V., Usman, P.K., 2007. Toxicity of organophosphates on morphology and locomotor behavior in brine shrimp, Artemia salina. Arch. Environ. Contam. Toxicol. 53, 227-232. 
1 Vidal, O., García-Berthou, E., Tedesco, P.A., García-Marín, J.L., 2010. Origin and genetic diversity of 12 mosquitofish (Gambusia holbrooki) introduced in Europe. Biol. Inv. 12, 841-851.

Wang, J.S., Simpson, K.L., 1998. Accumulation and depuration of DDTs in the food chain from Artemia 4 to Brook Trout (Salvelinus fontinalis). Bull. Environ. Contam. Toxicol. 56, 888-895.

5 Zalizniak, L., Nugegoda, D., 2006. Effect of sublethal concentrations of chlorpyrifos on three successive 6 generations of Daphnia carinata. Ecotoxicol. Environ. Safe. 64 207-214.

7 8 9

10 11

12

13

14

15

16

17

18

19

20

21

22

23

24

25

26

27

28

29

30

31

32

33

34

35

36

37

38

39

40

62

63

64

65 


\section{Figure legends}

2

3 Fig 1. Survival curves of A. franciscana and A. parthenogenetica exposed to different concentrations of 4 chlorpyrifos during life table experiments. (*) A. parthenogenetica individuals exposed to $5 \mu \mathrm{g} / \mathrm{l}$ of chlorpyrifos reached $100 \%$ mortality after 7 days (data not shown).

Fig 2. Principal Component Analysis (PCA) of the life table variables of $A$. franciscana and $A$. parthenogenetica exposed at different concentrations of chlorpyrifos. (A) Component plot. (B) Score plot: cases identified by species. (C) Score plot: cases identified by concentration of toxicant. For abbreviations see the text.

Fig 3. A. franciscana exposed to different concentrations of chlorpyrifos. (A) Effects of treatment on agespecific fertility measured relative to the control (C) (left), and contributions of these effects to the impact of chlorpyrifos on population growth rate (right). (B) Effects of treatment on age-specific survival probabilities measured relative to the control (C) (left), and contributions of these effects to the impact of chlorpyrifos on population growth rate (right).

Fig 4. A. parthenogenetica exposed to different concentrations of chlorpyrifos.(A) Effects of treatment on age-specific fertility measured relative to the control (C) (left), and contributions of these effects to the impact of chlorpyrifos on population growth rate (right). (B) Effects of chlorpyrifos treatment on agespecific survival probabilities measured relative to the control (C) (left), and contributions of these effects to the impact of chlorpyrifos on population growth rate (right).

Fig 5. Cholinesterase (ChE) activity in A. franciscana at different developmental stages after chronic exposure to different concentrations of chlorpyrifos. Values are given as means \pm SD (standard deviation); N=10-18. (A) Females and (B) males. (*) Denotes significant differences from control (C) (Dunnet's test, $\mathrm{P}<0.05$ ).

Fig 6. Cholinesterase (ChE) activity in A. parthenogenetica at different developmental stages after chronic exposure to different nominal concentrations of chlorpyrifos. Values are given as means \pm SD (standard deviation); $\mathrm{N}=10-16$ individuals. (*) Denotes significant differences from control (C) (Dunnet's test, $\mathrm{P}<0.05)$.

Fig 7. Cholinesterase (ChE) activity in non-exposed (C: control group) individuals of A. franciscana and A. parthenogenetica at different developmental stages. Values are given means \pm SD (standard deviation); $\mathrm{N}=10-18$ individuals. Mn: metanauplii, JM: juvenile male, JF: juvenile female, AM: adult male, AF: adult female, J: juvenile, A: adult. (*) Denotes significant differences (Tukey’s test, $\mathrm{P}<0.05$ ). 
Table 1 Reproductive parameters obtained from life table experiments for A. franciscana (AF) exposed to different concentration of chlorpyrifos. Mean \pm $\mathrm{SD}$ (standard deviation). See text for more details.

\begin{tabular}{|c|c|c|c|c|c|}
\hline \multirow{2}{*}{$\begin{array}{l}\text { Reproductive } \\
\text { parameters }\end{array}$} & \multicolumn{5}{|c|}{ Chlorpyrifos concentrations } \\
\hline & $\mathrm{C}$ & $\mathrm{CA}$ & $0.1 \mu \mathrm{g} / 1$ & $1 \mu \mathrm{g} / 1$ & $5 \mu \mathrm{g} / 1$ \\
\hline \multicolumn{6}{|c|}{ Temporal parameters } \\
\hline PRP (days) & $19.63 \pm 2.03$ & $19.80 \pm 1.06$ & $19.39 \pm 1.79$ & $18.05 \pm 2.37$ & $19.11 \pm 1.88$ \\
\hline P/B (days) & $5.12 \pm 0.48$ & $4.83 \pm 0.48$ & $4.87 \pm 0.38$ & $4.71 \pm 0.42$ & $4.73 \pm 0.87$ \\
\hline \multicolumn{6}{|l|}{ Fecundity } \\
\hline B & $7.32 \pm 1.63^{\mathrm{ab}}$ & $6.25 \pm 1.89^{b}$ & $7.56 \pm 2.23^{\mathrm{ab}}$ & $8.58 \pm 1.35^{\mathrm{a}}$ & $6.05 \pm 2.01^{\mathrm{b}}$ \\
\hline OFF & $1194.89 \pm 331.11^{\mathrm{ab}}$ & $999.00 \pm 378.36^{b}$ & $1227.72 \pm 449.97^{\mathrm{ab}}$ & $1410.58 \pm 337.95^{\mathrm{a}}$ & $1031.21 \pm 448.08^{b}$ \\
\hline $\mathrm{OFF} / \mathrm{B}$ & $162.03 \pm 34.67$ & $158.38 \pm 30.82$ & $162.45 \pm 30.19$ & $163.69 \pm 26.24$ & $165.49 \pm 38.25$ \\
\hline \multicolumn{6}{|c|}{ Type of reproduction } \\
\hline OVO $(\%)$ & $38.35 \pm 28.02$ & $27.94 \pm 32.60$ & $26.54 \pm 35.54$ & $34.53 \pm 35.97$ & $43.31 \pm 31.94$ \\
\hline OVIP (\%) & $61.65 \pm 28.02$ & $72.06 \pm 32.60$ & $73.46 \pm 35.54$ & $65.47 \pm 35.97$ & $56.69 \pm 31.94$ \\
\hline \multicolumn{6}{|c|}{ Quality of reproduction } \\
\hline $\mathrm{VN}(\%)$ & $95.81 \pm 9.64$ & $95.25 \pm 7.06$ & $98.42 \pm 1.33$ & $88.79 \pm 27.74$ & $80.30 \pm 28.27$ \\
\hline NVN (\%) & $4.19 \pm 9.64$ & $4.75 \pm 7,06$ & $1.42 \pm 1.35$ & $11.15 \pm 27.76$ & $19.70 \pm 28.27$ \\
\hline $\mathrm{VC}(\%)$ & $99.09 \pm 2.07$ & $98.37 \pm 5.31$ & $95.17 \pm 8.17$ & $88.84 \pm 12.38 *$ & $79.66 \pm 30.18$ \\
\hline $\operatorname{NVC}(\%)$ & $0.91 \pm 2.07$ & $1.63 \pm 5.31$ & $4.83 \pm 8.17$ & $11.16 \pm 12.38 *$ & $20.34 \pm 30.18$ \\
\hline
\end{tabular}

Different letters within the same row denotes significant differences (post hoc Turkey's test, $\mathrm{p}<0.05$ )

(*) Indicates significant differences from $C$ (control group) (Games-Howell 's test, $\mathrm{p}<0.05$ )

PRP: pre-reproductive period; P/B: period between broods; B: total number of broods per female; OFF: total offspring per female; OFF/B: total offspring per brood;

OVO: ovoviviparous (nauplii); OVIP: cysts; VN: viable nauplii; NVN: dead plus abortive embryos; VC: viable cysts; NVC: non-viable cysts. 
Table 2 Reproductive parameters obtained from life table experiments for A. parthenogenetica (PD) exposed to different concentration of chlorpyrifos.

Mean \pm SD (standard deviation). See text for more details.

\begin{tabular}{|c|c|c|c|c|c|}
\hline \multirow{2}{*}{$\begin{array}{l}\text { Reproductive } \\
\text { parameters }\end{array}$} & \multicolumn{5}{|c|}{ Chlorpyrifos concentrations } \\
\hline & $\mathrm{C}$ & $\mathrm{CA}$ & $0.1 \mu \mathrm{g} / \mathrm{l}$ & $1 \mu \mathrm{g} / 1$ & $5 \mu \mathrm{g} / 1$ \\
\hline \multicolumn{6}{|c|}{ Temporal parameters } \\
\hline PRP (days) & $31.93 \pm 4.29$ & $32.38 \pm 3.99$ & $32.06 \pm 3.92$ & $29.56 \pm 3.0$ & - \\
\hline P/B (days) & $5.94 \pm 0.53^{\mathrm{a}}$ & $5.74 \pm 0.31^{a b}$ & $6.02 \pm 0.72^{\mathrm{a}}$ & $5.19 \pm 0.45^{b}$ & - \\
\hline \multicolumn{6}{|l|}{ Fecundity } \\
\hline B & $4.71 \pm 1.49^{\mathrm{ab}}$ & $5.08 \pm 1.55^{\mathrm{a}}$ & $3.69 \pm 0.70^{b}$ & $3.44 \pm 0.53^{\mathrm{c}}$ & - \\
\hline OFF & $584.93 \pm 363.99$ & $587.08 \pm 242.80$ & $394.44 \pm 141.53$ & $258.11 \pm 83.94 *$ & - \\
\hline $\mathrm{OFF} / \mathrm{B}$ & $117.72 \pm 49.44$ & $113.46 \pm 30.36$ & $106.0 \pm 28.61$ & $74.07 \pm 16.40^{* *}$ & - \\
\hline \multicolumn{6}{|c|}{ Type of reproduction } \\
\hline OVO $(\%)$ & $17.02 \pm 27.84$ & $20.39 \pm 16.18$ & $7.38 \pm 15.08$ & $44.72 \pm 34.30$ & - \\
\hline OVIP $(\%)$ & $82.98 \pm 27.84$ & $79.61 \pm 16.18$ & $92.62 \pm 15.08$ & $55.28 \pm 34.30$ & - \\
\hline \multicolumn{6}{|c|}{ Quality of reproduction } \\
\hline $\mathrm{VN}(\%)$ & $62.70 \pm 36.74$ & $63.40 \pm 29.18$ & $68.63 \pm 34.68$ & $71.65 \pm 20.09$ & - \\
\hline $\operatorname{NVN}(\%)$ & $37.30 \pm 36.38$ & $36.60 \pm 29.18$ & $31.37 \pm 34.68$ & $28.35 \pm 20.09$ & - \\
\hline $\mathrm{VC}(\%)$ & $78.79 \pm 24.20$ & $84.88 \pm 19.33$ & $92.45 \pm 10.98$ & $91.09 \pm 14.01$ & - \\
\hline $\operatorname{NVC}(\%)$ & $21.21 \pm 24.20$ & $15.12 \pm 19.33$ & $7.55 \pm 10.98$ & $8.91 \pm 14.01$ & - \\
\hline
\end{tabular}

Different letters within the same row denotes significant differences (post hoc Turkey's test, $\mathrm{p}<0.05$ )

(*) Indicates significant differences from all groups (Games-Howell 's test, $\mathrm{p}<0.05$ )

(**) Indicates significant differences from $\mathrm{C}$ (Games-Howell 's test, $\mathrm{p}<0.05$ )

PRP: pre-reproductive period; P/B: period between broods; B: total number of broods per female; OFF: total offspring per female; OFF/B: total offspring per brood;

OVO: ovoviviparous (nauplii); OVIP: cysts; VN: viable nauplii; NVN: dead plus abortive embryos; VC: viable cysts; NVC: non-viable cysts 
Table 3 Population growth rate $(\lambda)$ in A. franciscana (AF) and A.parthenogenetica (PD) populations for the different treatments assayed. Values in brackets indicate percentage deviation from control (C).

\begin{tabular}{lccccc}
\hline \multirow{2}{*}{ Species } & \multicolumn{4}{c}{ Chlorpyrifos concentrations } \\
\cline { 2 - 6 } & $\mathrm{C}$ & $\mathrm{CA}$ & $0.1 \mu \mathrm{g} / 1$ & $1 \mu \mathrm{g} / 1$ & $5 \mu \mathrm{g} / 1$ \\
\hline $\mathrm{AF}$ & 2.72 & $2.44(-10.3)$ & $2.49(-8.5)$ & $2.41(-11.4)$ & $2.35(-13.6)$ \\
$\mathrm{PD}$ & 1.88 & $1.83(-2.6)$ & $1.59(-15.4)$ & $-45(-22.9)$ & - \\
\hline
\end{tabular}


Fig.1
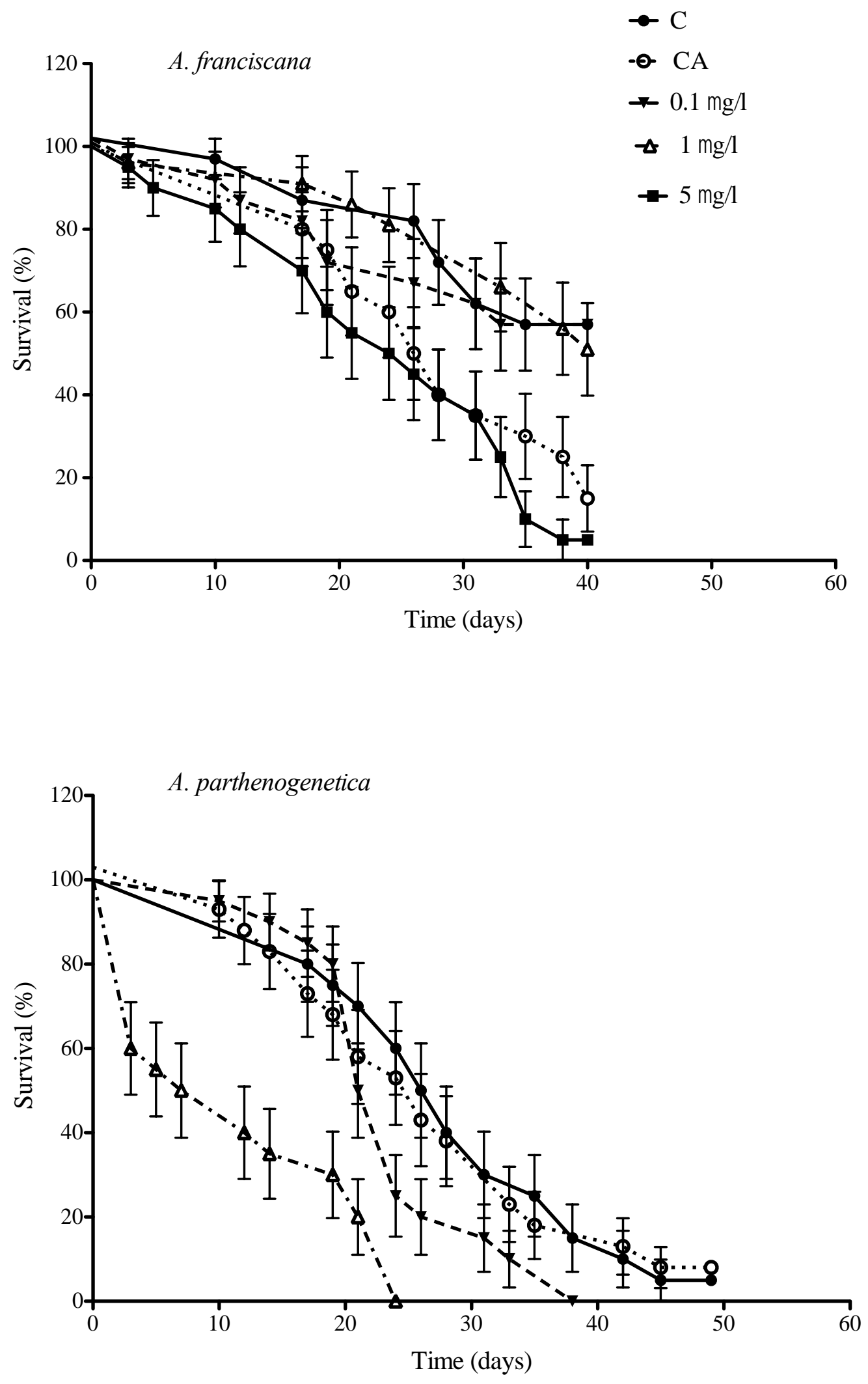
Fig 2

A

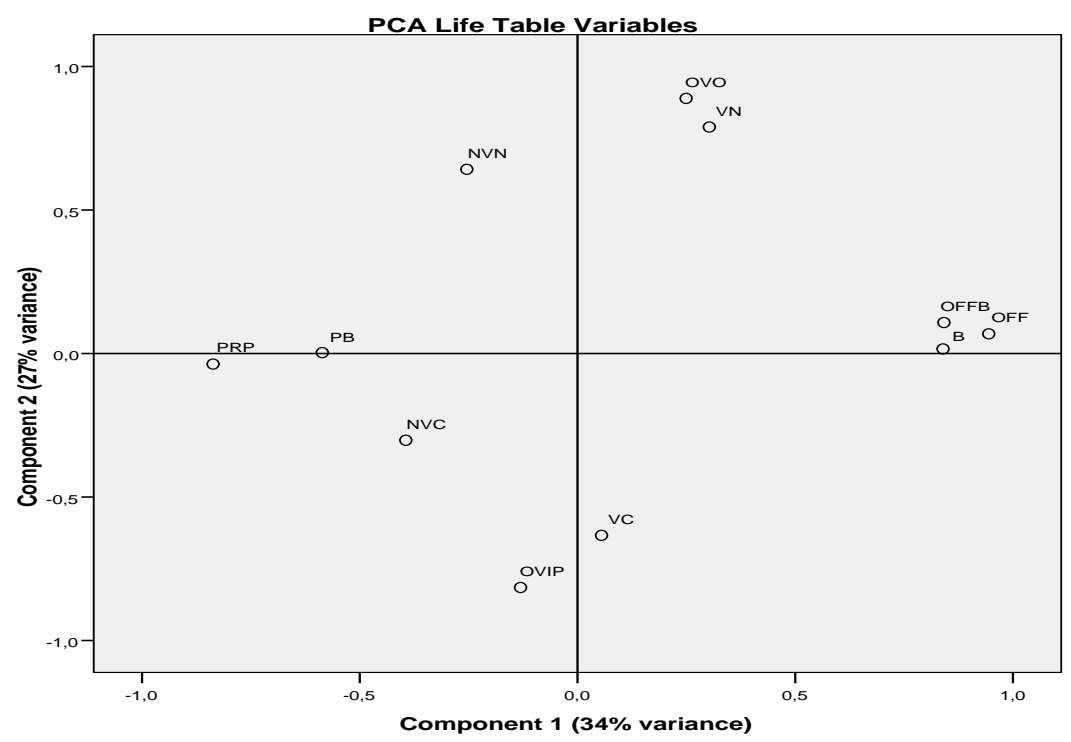

B

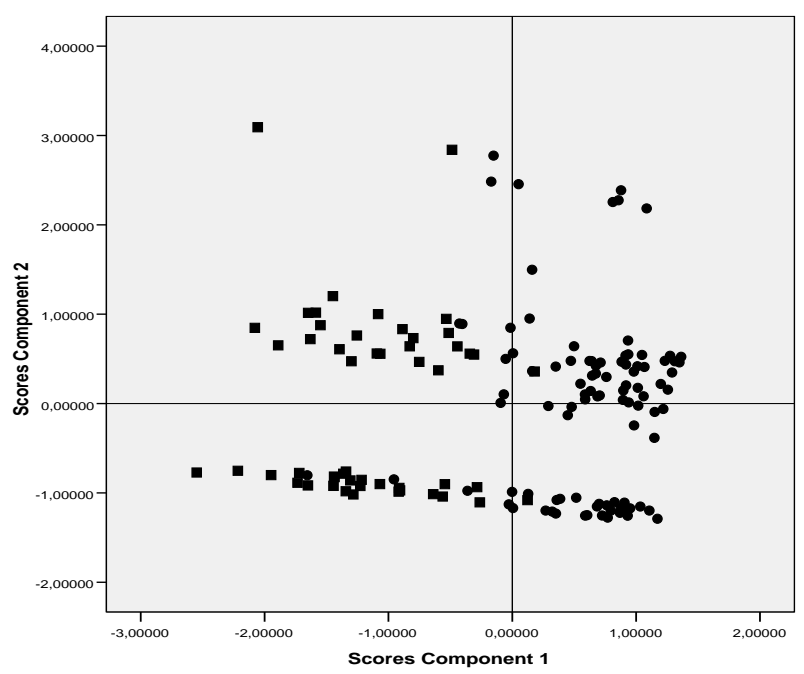

C

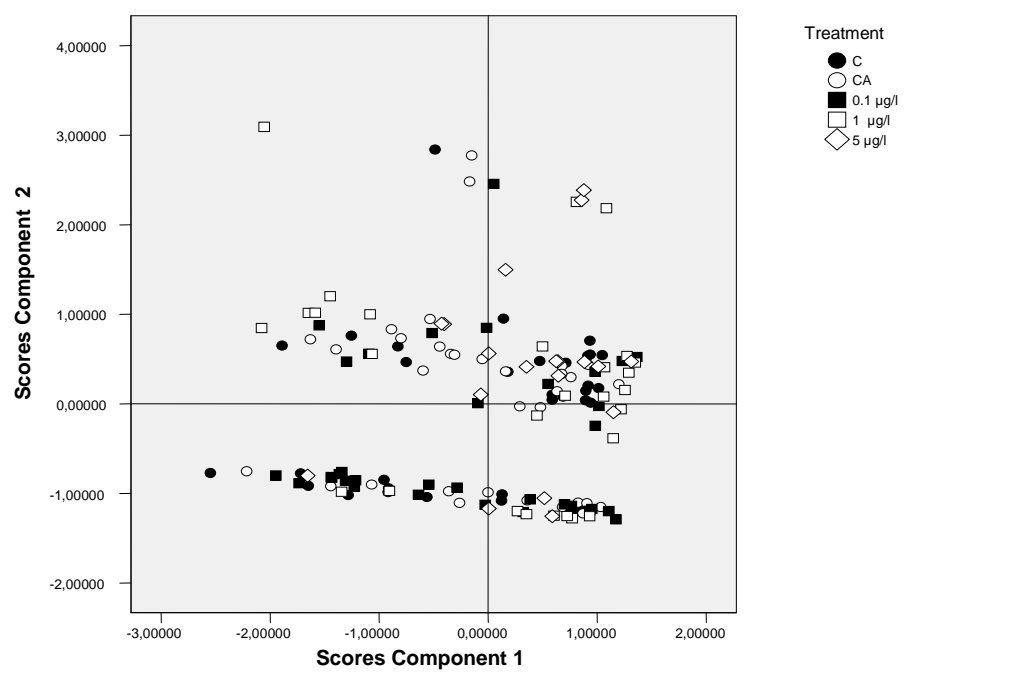


Fig 3

A
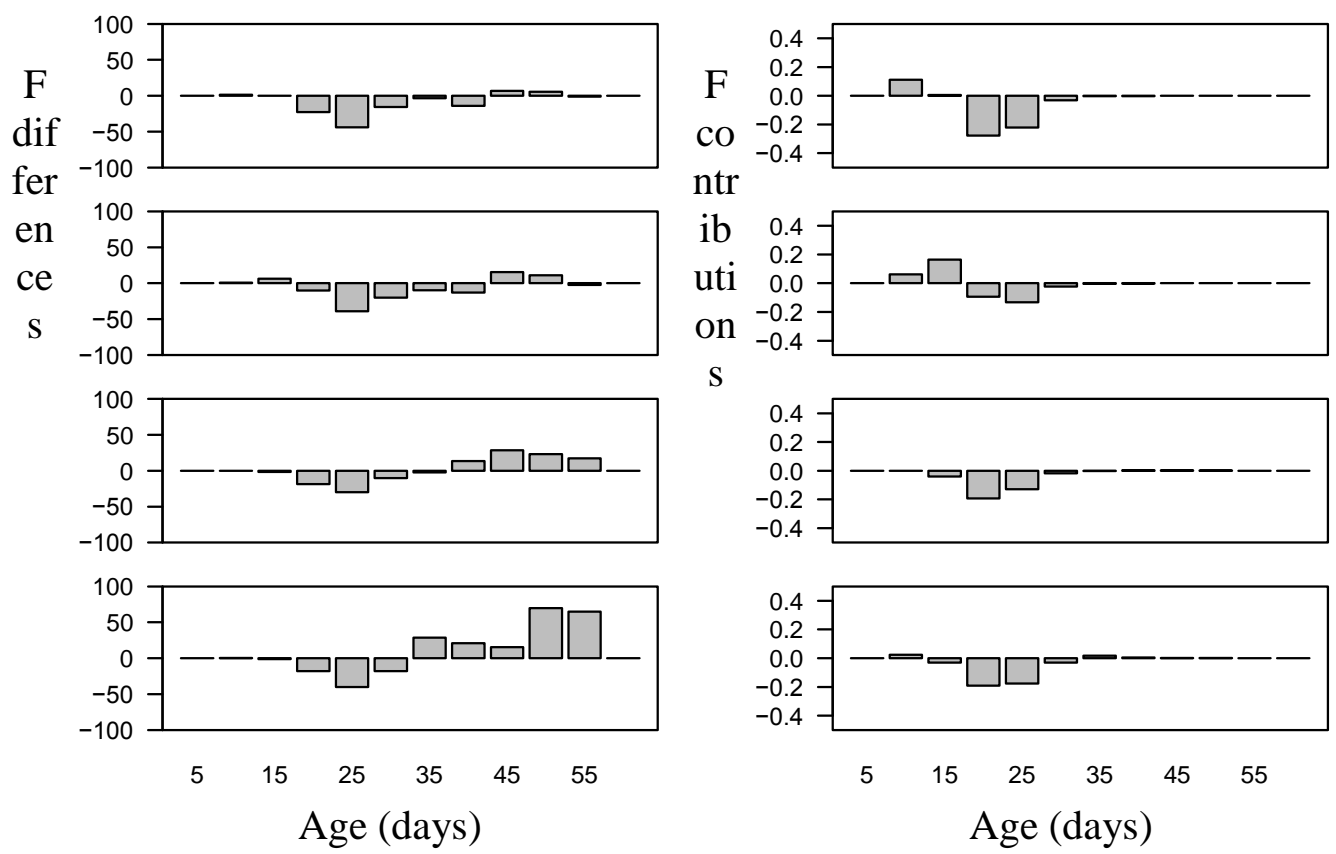

$\mathrm{s}$
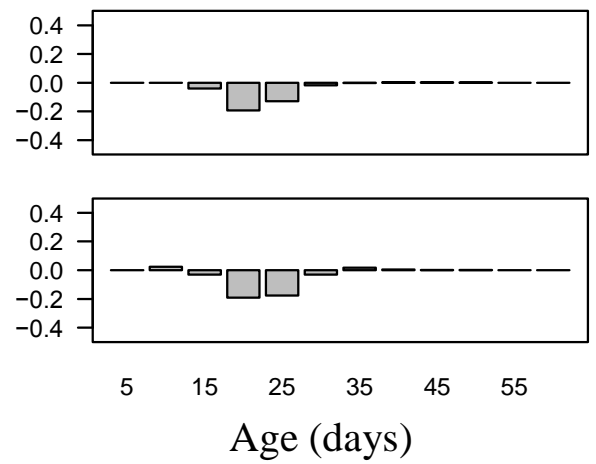

B
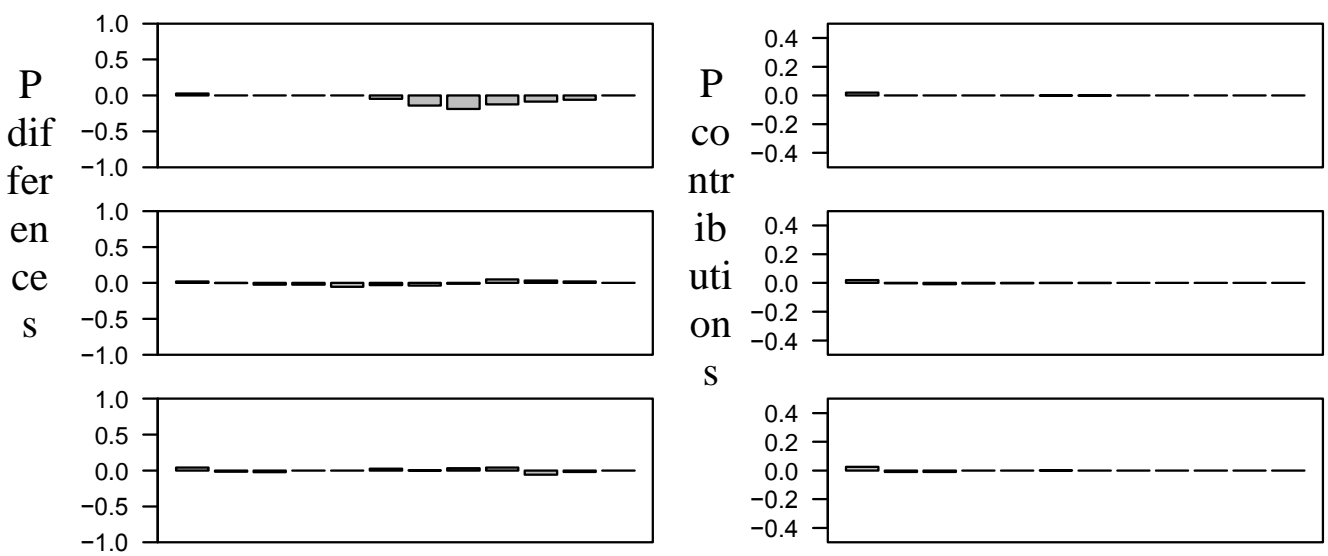

$\mathrm{ntr}$

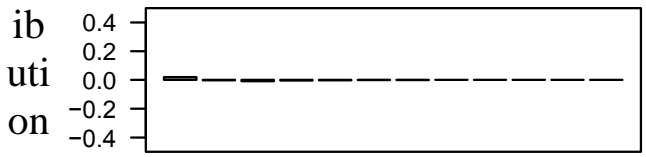

$\mathrm{S}$
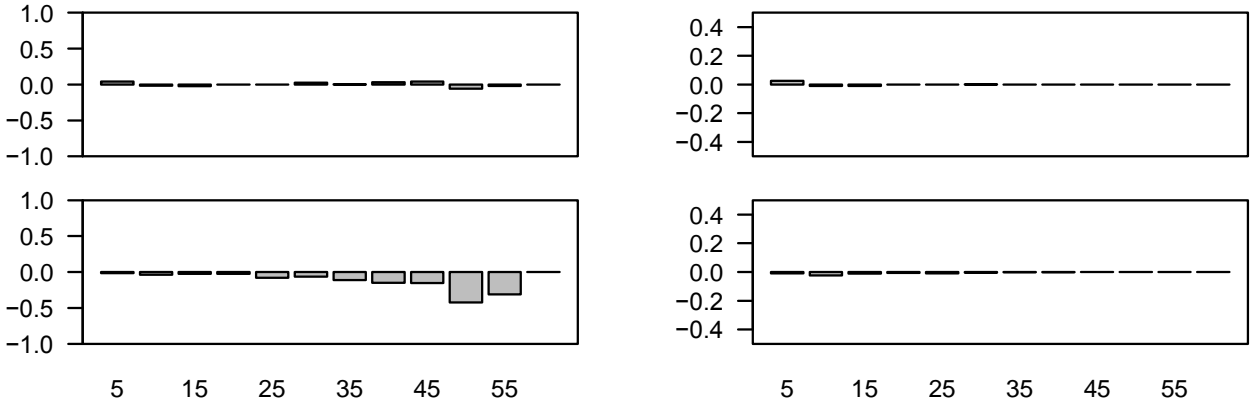

Age (days)

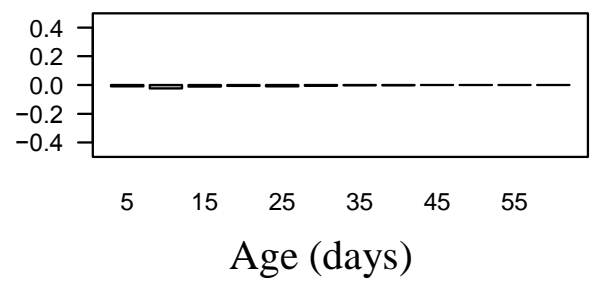


Fig.4

A
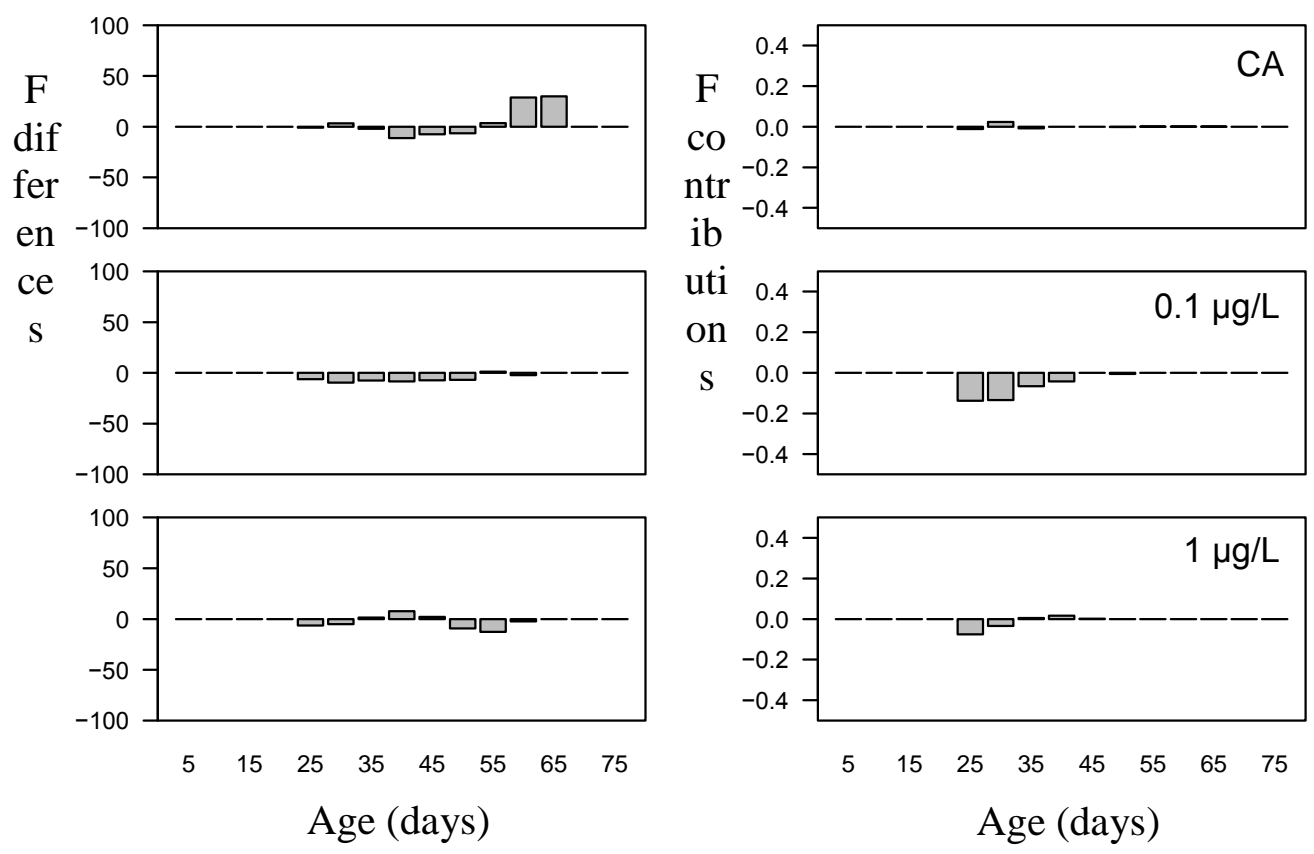

B
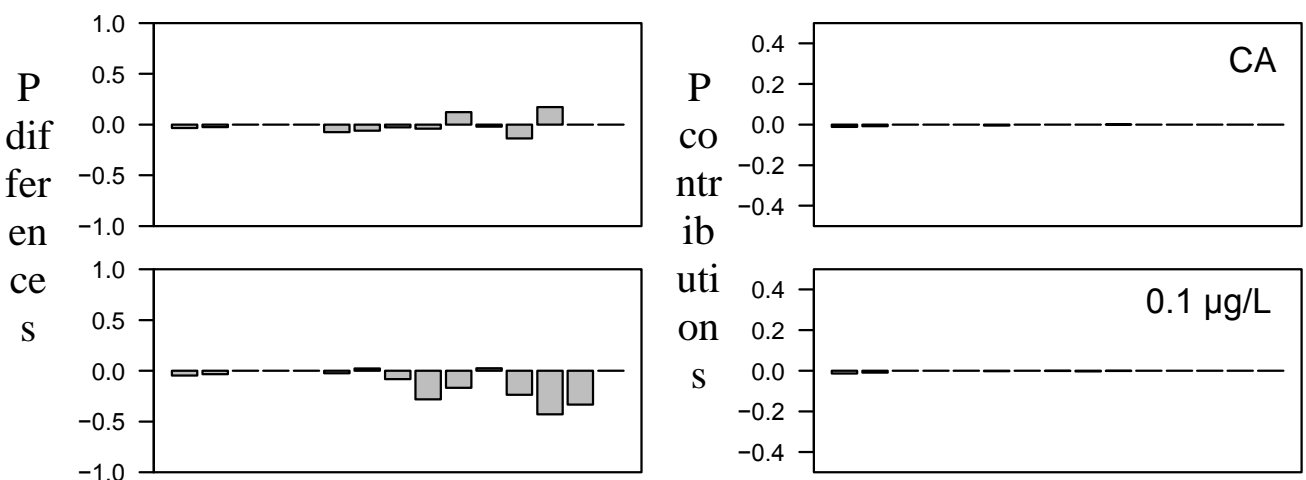

$\mathrm{ib}$
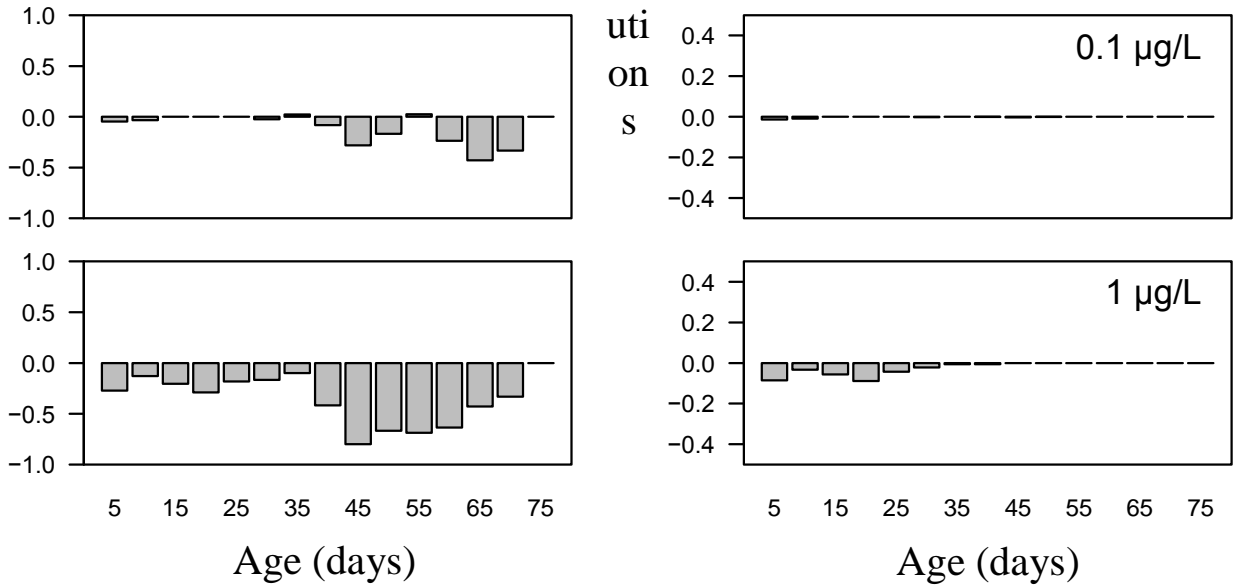
Fig 5
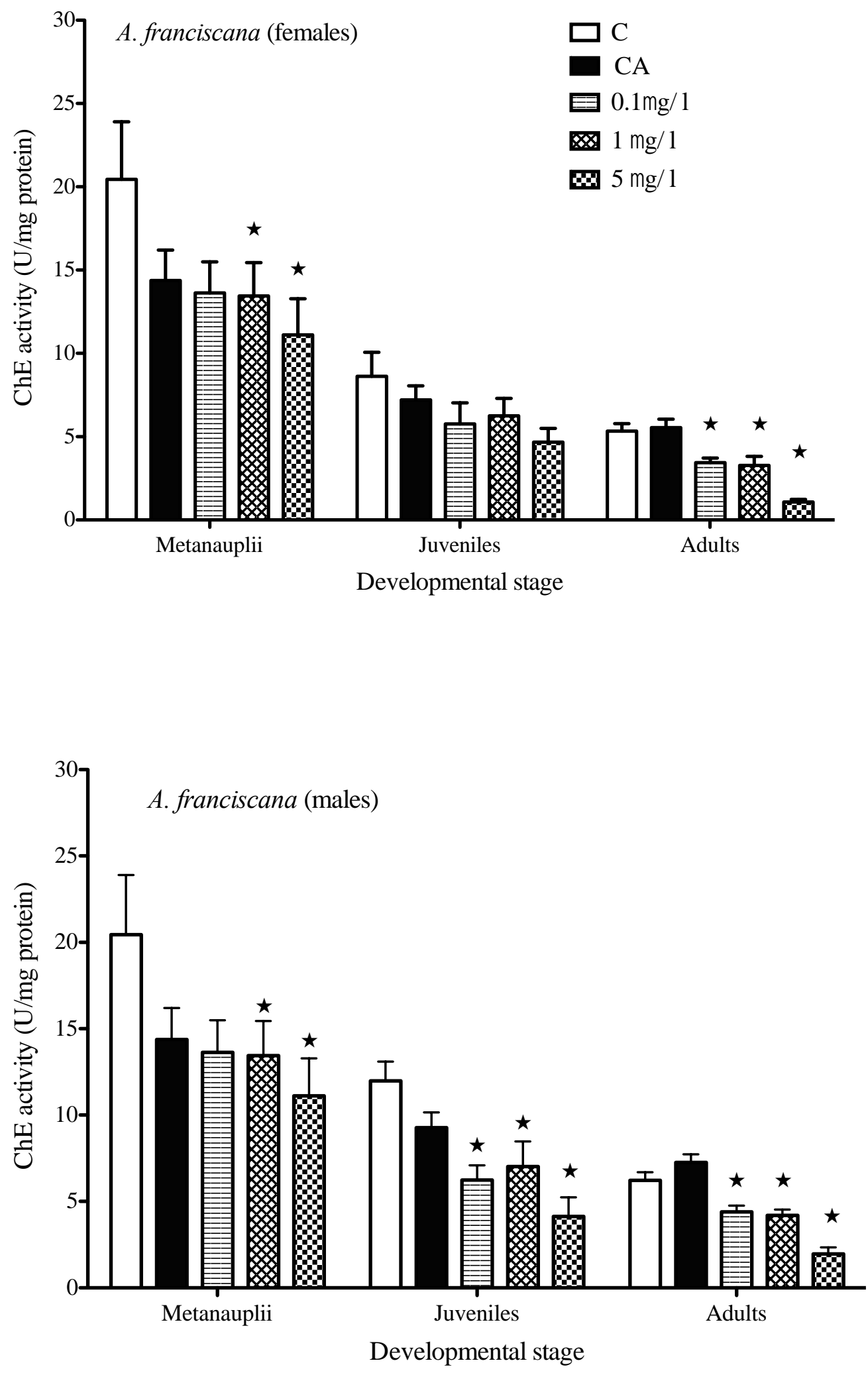
Fig 6

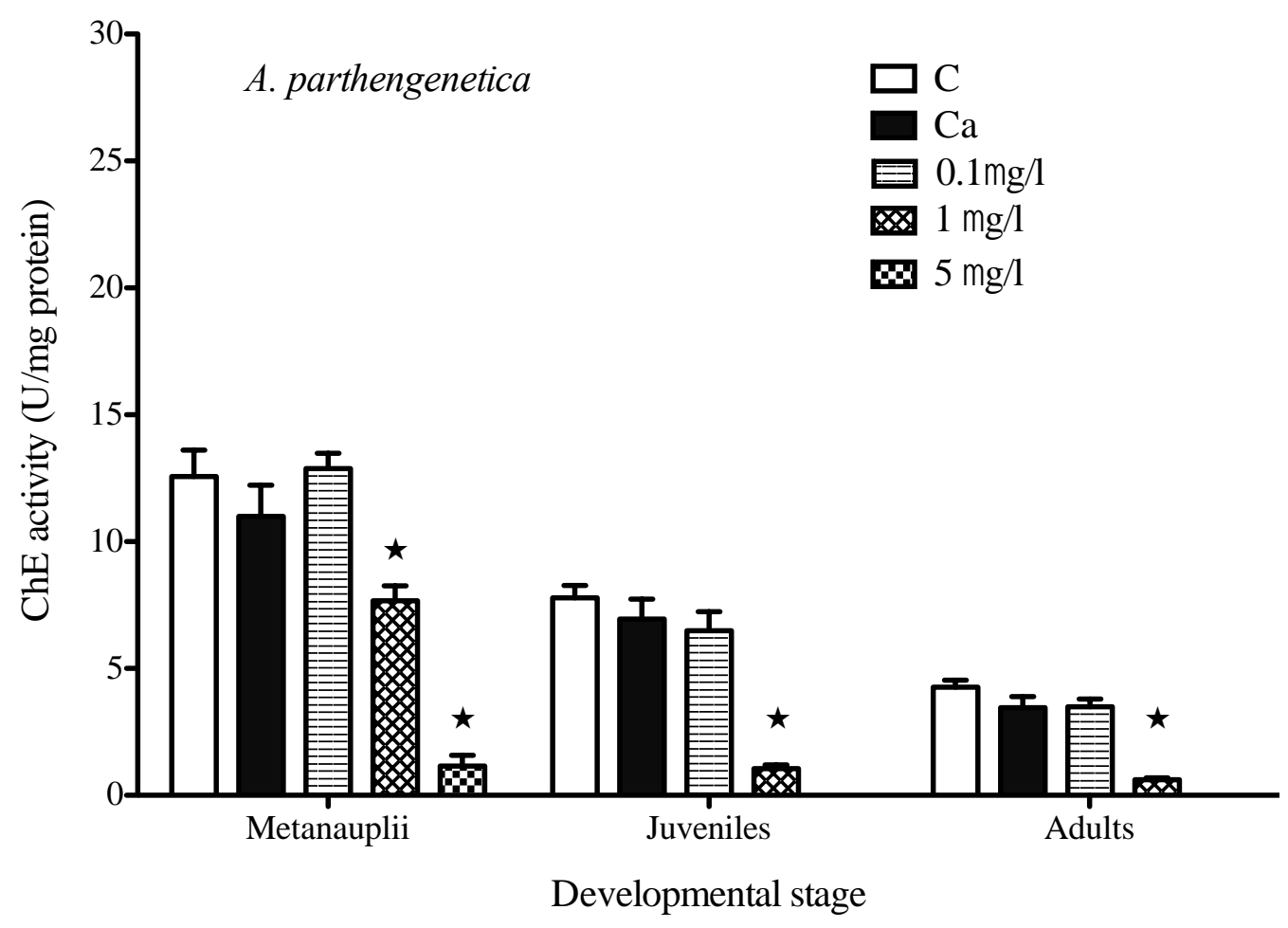


Fig 7
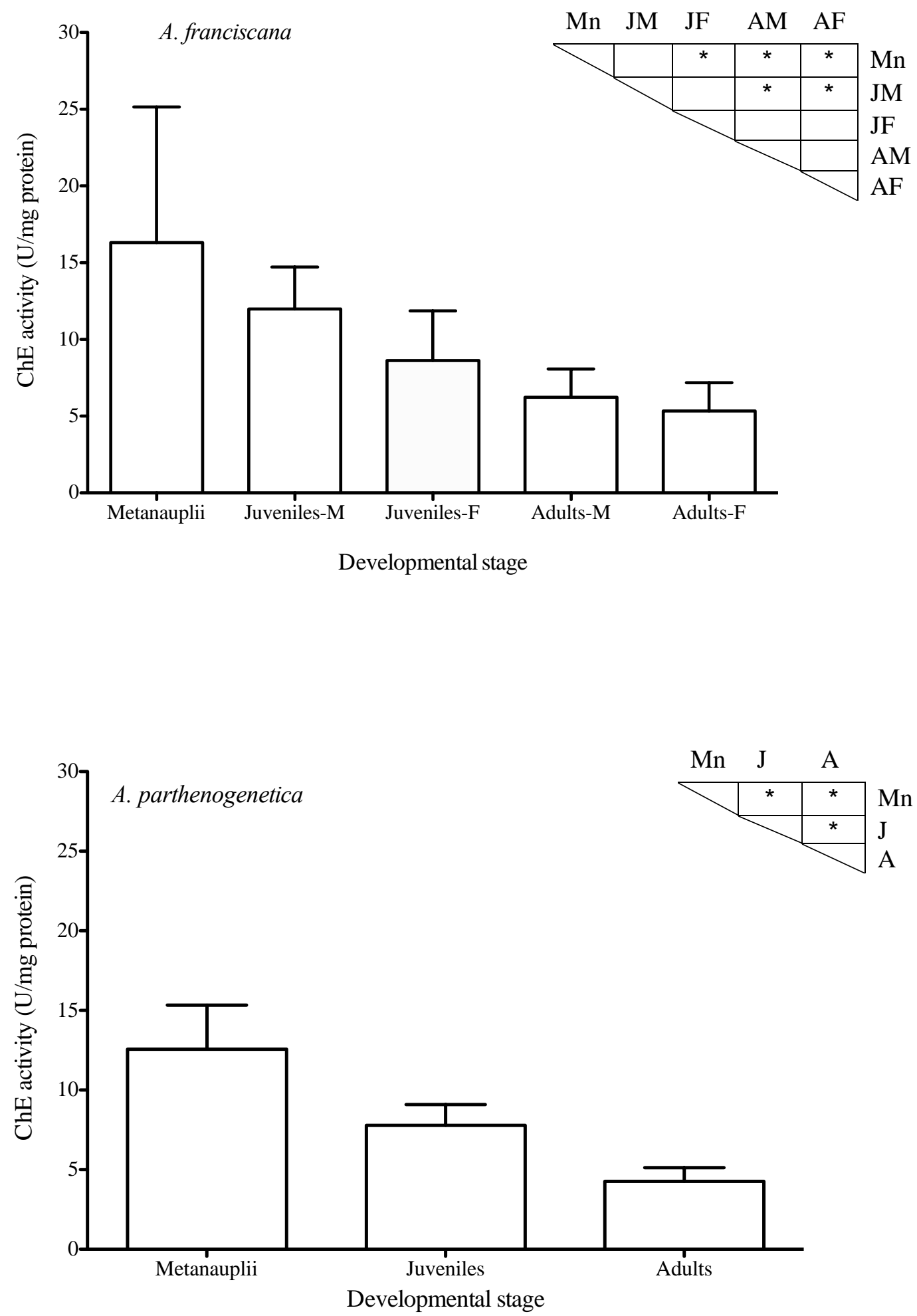
- Artemia species display an elevated tolerance to high ranges of chlorpyrifos.

- A. franciscana survived better and its fecundity was less affected by chlorpyrifos.

- The higher fecundity of A. franciscana is a selective advantage in colonization processes.

- Higher survival and biological fitness in A. franciscana indicate out-competitive advantages. 